\title{
Intracellular calcium stores drive slow non-ribbon vesicle release from rod photoreceptors
}

\author{
Minghui Chen ${ }^{1,2}$, David Križaj ${ }^{3}$ and Wallace B. Thoreson ${ }^{1,2}$ * \\ 1 Department of Pharmacology and Experimental Neuroscience, University of Nebraska Medical Center, Omaha, NE, USA \\ ${ }^{2}$ Department of Ophthalmology and Visual Sciences, University of Nebraska Medical Center, Omaha, NE, USA \\ ${ }^{3}$ Department of Ophthalmology and Visual Sciences, Moran Eye Center, University of Utah School of Medicine, Salt Lake City, UT, USA
}

\section{Edited by:}

Arianna Maffei, State University of

New York at Stony Brook, USA

\section{Reviewed by:}

Johann Helmut Brandstaetter,

Friedrich-Alexander-Universität Erlangen-Nürnberg, Germany

Nicholas Brecha, University of

California at Los Angeles School of

Medicine, USA

*Correspondence:

Wallace B. Thoreson, Department of Ophthalmology and Visual Sciences, University of Nebraska Medical Center, 4050 Durham Research Center I, Omaha, NE 68198-5840, USA

e-mail:wbthores@unmc.edu
Rods are capable of greater slow release than cones contributing to overall slower release kinetics. Slow release in rods involves $\mathrm{Ca}^{2+}$-induced $\mathrm{Ca}^{2+}$ release $(\mathrm{CICR})$. By impairing release from ribbons, we found that unlike cones where release occurs entirely at ribbonstyle active zones, slow release from rods occurs mostly at ectopic, non-ribbon sites. To investigate the role of $\mathrm{CICR}$ in ribbon and non-ribbon release from rods, we used total internal reflection fluorescence microscopy as a tool for visualizing terminals of isolated rods loaded with fluorescent $\mathrm{Ca}^{2+}$ indicator dyes and synaptic vesicles loaded with dextranconjugated $\mathrm{pH}$-sensitive rhodamine. We found that rather than simply facilitating release, activation of $\mathrm{CICR}$ by ryanodine triggered release directly in rods, independent of plasma membrane $\mathrm{Ca}^{2+}$ channel activation. Ryanodine-evoked release occurred mostly at nonribbon sites and release evoked by sustained depolarization at non-ribbon sites was mostly due to $\mathrm{CICR}$. Unlike release at ribbon-style active zones, non-ribbon release did not occur at fixed locations. Fluorescence recovery after photobleaching of endoplasmic reticulum (ER)tracker dye in rod terminals showed that ER extends continuously from synapse to soma. Release of $\mathrm{Ca}^{2+}$ from terminal ER by lengthy depolarization did not significantly deplete $\mathrm{Ca}^{2+}$ from ER in the perikaryon. Collectively, these results indicate that CICR-triggered release at non-ribbon sites is a major mechanism for maintaining vesicle release from rods and that $\mathrm{CICR}$ in terminals may be sustained by diffusion of $\mathrm{Ca}^{2+}$ through ER from other parts of the cell.

Keywords: calcium-induced calcium release, ryanodine receptors, exocytosis, ribbon synapse, retina, synaptic vesicle, total internal reflection fluorescence microscopy

\section{INTRODUCTION}

Light-evoked voltage changes in photoreceptor cells are transmitted to second-order retinal neurons by changing the rate of glutamate release. In cones, glutamate release is thought to occur almost exclusively at plate-like synaptic ribbons (Jackman et al., 2009; Snellman et al., 2011) where depolarization at light offset stimulates rapid release of vesicles tethered at the base of the ribbon (Bartoletti et al., 2010; Snellman et al., 2011). During maintained depolarization, the rate of release declines and is governed by the rate that vesicles replenish release sites at the base of the ribbon (Jackman et al., 2009; Snellman et al., 2011).

Although rods are also capable of fast release (Li et al., 2010), rods exhibit considerably greater slow release than cones when stimulated with long (>100 ms) depolarizing steps, contributing to overall slower release kinetics (Schnapf and Copenhagen, 1982; Cadetti et al., 2005; Rabl et al., 2005). Using total internal reflection fluorescence microscopy (TIRFM) to visualize fusion of synaptic vesicles in rods loaded with dextran-conjugated $\mathrm{pH}$ sensitive rhodamine (pHrodo), many of the vesicle fusion events evoked by long depolarizing steps were found to occur at sites $>1 \mu \mathrm{m}$ from ribbons (Chen et al., 2013). Furthermore, damaging ribbons by fluorophore-assisted laser inactivation (FALI) of the ribbon protein Ribeye selectively diminished exocytotic increases in membrane capacitance evoked by short test steps but not capacitance increases evoked by longer steps (Chen et al., 2013). These results suggest that fast release from rods involves the ribbon but slow release involves non-ribbon release sites. Also consistent with contributions from non-ribbon release sites in rods are the presence of putative fusion events at non-ribbon sites revealed by electron microscopic (EM) tomography (Zampighi et al., 2011).

In addition to non-ribbon release, slow release from rods, but not cones, also involves $\mathrm{Ca}^{2+}$-induced $\mathrm{Ca}^{2+}$ release (CICR; Križaj et al., 1999; Cadetti et al., 2006; Suryanarayanan and Slaughter, 2006; Babai et al., 2010b). Blocking CICR strongly inhibited light responses in second-order neurons from mammalian and amphibian retina suggesting that CICR is essential for maintaining sustained release from rods in darkness (Cadetti et al., 2006; Suryanarayanan and Slaughter, 2006; Babai et al., 2010b). CICR has been shown to promote spontaneous (Emptage et al., 2001; Bardo et al., 2002; Simkus and Stricker, 2002) and evoked synaptic release in a number of neurons (Ludwig et al., 2002; Galante and Marty, 2003; Trueta et al., 2003). It typically does so by enhancing vesicle priming (Ludwig et al., 2002, 2005; Tobin et al., 2012), increasing vesicle mobility (Shakiryanova et al., 2007), or sensitizing vesicles to forthcoming depolarization (Llano et al., 2000; Galante and Marty, 2003). However, the unusually high $\mathrm{Ca}^{2+}$ 
sensitivity of exocytotic sensors in rods (Thoreson et al., 2004) raised the possibility that CICR may trigger release directly in rods.

In the present study, we tested the hypothesis that slow release from rods involves CICR-triggered release of vesicles at nonribbon sites. To test this hypothesis, we combined electrophysiological recordings and TIRFM visualization of submembrane $\mathrm{Ca}^{2+}$ changes and vesicle fusion events (Chen et al., 2013). The results showed that most of the slow synaptic release from rods is due to vesicle fusion at non-ribbon sites triggered by CICR. The results also suggest that CICR-driven release may be sustained by $\mathrm{Ca}^{2+}$ ions diffusing through the endoplasmic reticulum (ER) from perikaryon to synapse.

\section{MATERIALS AND METHODS ANIMAL CARE AND USE}

Aquatic tiger salamanders (Ambystoma tigrinum, $18-25 \mathrm{~cm}$ in length; Charles Sullivan Co., Nashville, TN, USA) were maintained on a 12-h light/dark cycle and killed 1-2 $\mathrm{h}$ after the beginning of subjective night. Salamanders were decapitated with heavy shears, the head was hemisected and the spinal cord pithed. Protocols were approved by the University of Nebraska Medical Center Institutional Animal Care and Use Committee.

\section{PAIRED RECORDINGS FROM RODS AND HORIZONTAL CELLS}

To measure release from rods electrophysiologically, we obtained paired whole cell recordings from rods and horizontal cells in a retina slice preparation. Details of slice preparation and electrophysiological recordings are described in detail elsewhere (Van Hook and Thoreson, 2013). Briefly, retinal slices (125 $\mu \mathrm{m})$ were placed under a water-immersion objective $(60 \times, 1.0 \mathrm{NA})$ on an upright fixed-stage microscope (Nikon E600FN) and superfused at $\sim 1 \mathrm{ml} / \mathrm{min}$ with an oxygenated amphibian saline solution containing (in mM): $116 \mathrm{NaCl}, 2.5 \mathrm{KCl}, 1.8 \mathrm{CaCl}_{2}, 0.5 \mathrm{MgCl}_{2}, 10 \mathrm{~N}$-2hydroxyethylpiperazine- $N^{\prime}$-2-ethanesulfonic acid (HEPES), and 5 glucose ( $\mathrm{pH} 7.8$ ). Rods and horizontal cells were simultaneously voltage clamped using Optopatch (Cairn Research) and Axopatch 200B (Molecular Devices) patch-clamp amplifiers. Recording pipettes were pulled on a PP-830 vertical puller (Narishige International USA, East Meadow, NY, USA) from borosilicate glass pipettes (1.2- $\mathrm{mm}$ outer diameter, 0.9- $\mathrm{mm}$ inner diameter, with internal filament; World Precision Instruments, Sarasota, FL, USA). Pipette resistance was 12-18 M 2 . Rod pipettes were filled with (in $\mathrm{mM}$ ): 40 cesium glutamate, 50 cesium gluconate, 9.4 tetraethylammonium chloride (TEACl), $3.5 \mathrm{NaCl}, 1 \mathrm{MgCl}_{2}, 9.4$ MgATP, 0.5 GTP, 5 ethylene glycol tetraacetic acid (EGTA), 1 reduced glutathione, 16 -hydroxy-2,5,7,8-tetramethylchroman-2carboxylic acid (Trolox), 10 HEPES ( $\mathrm{pH}$ 7.2). Horizontal cell pipettes contained (in $\mathrm{mM}$ ): 90 cesium gluconate, $10 \mathrm{TEACl}, 1$ $\mathrm{CaCl}_{2}$, 3.5 NaCl, $1 \mathrm{MgCl}_{2}$, 9.4 MgATP, 0.5 GTP, 5 EGTA, 10 HEPES ( $\mathrm{pH}$ 7.2). Unless otherwise specified, reagents were obtained from Sigma-Aldrich Chemicals (St. Louis, MO, USA). Currents were acquired and analyzed using pClamp 9.2 software with Digidata 1322 interface (Molecular Devices).

To selectively damage ribbons, we used FALI with a fluoresceinconjugated Ribeye-binding peptide $(80 \mu \mathrm{M})$ added to the presynaptic patch pipette solution. The Ribeye-binding peptide
(EQTVPVDLSVARPR) contains a PXDLS sequence that binds selectively to the C-terminal binding protein (CtBP) domain of Ribeye (Zenisek et al., 2004). After waiting $>10 \mathrm{~min}$ for diffusion into the cell, the peptide was bleached by $50 \mathrm{~s}$ exposure to 488-nm light from an $\mathrm{Ar} / \mathrm{Kr}$ laser delivered through a laser confocal scan head (PerkinElmer Ultraview LCI, Waltham, MA, USA) mounted to an upright, fixed-stage microscope (Nikon E600FN; Snellman et al., 2011). Excitation of the fluorescein moiety by $488 \mathrm{~nm}$ laser light generates singlet oxygen producing half-maximal damage within $\sim 40 \AA$ of the fluorophore (HoffmanKim et al., 2007). As a control, we used a scrambled version of the same fluorescein-conjugated peptide. Ribeye-binding peptide or the scrambled control peptide were added to the pipette solution together with the anti-oxidants reduced glutathione (1 mM) and 6hydroxy-2,5,7,8-tetramethylchroman-2-carboxylic acid (Trolox, $1 \mathrm{mM})$.

To block synaptic vesicle release, botulinum toxin E light chain (500 nM), which cleaves the SNARE (soluble $N$-ethylmaleimidesensitive factor attachment protein receptor) proteins SNAP-23 and SNAP-25, was added to the presynaptic patch pipette solution in some experiments.

\section{LOADING SYNAPTIC VESICLES WITH DEXTRAN-CONJUGATED pHrodo}

Synaptic vesicles were visualized by TIRFM as described previously (Chen et al., 2013). Briefly, retinas were isolated and incubated with a dextran (10,000 MW)-conjugated, $\mathrm{pH}$-sensitive form of rhodamine, pHrodo $(500 \mu \mathrm{g} / \mathrm{ml}$, Invitrogen, Grand Island, NY, USA) in amphibian saline at $20^{\circ} \mathrm{C}$. During dissection and dye incubation, retinas were maintained in darkness using night vision goggles (Nitemate NAV3, Litton Industries, Tempe, AZ, USA). The depolarized membrane potential of rods in darkness stimulates continuous release of vesicles, followed by endocytosis and uptake of pHrodo. Dextran-conjugated pHrodo is watersoluble and its fluorescence increases in the acidic interior of synaptic vesicles. Fluorescence of pHrodo declines considerably at an extracellular $\mathrm{pH}$ of 7.8. After loading vesicles, retinas were exposed to light to hyperpolarize the rods and placed in a $\mathrm{Ca}^{2+}$ free amphibian saline to inhibit further exocytosis. For some experiments, we used 30-min incubation to load a large portion of the vesicle population. For other experiments, we used a short incubation time ( $3 \mathrm{~min}$ ) to load $1-3 \%$ of the vesicle pool (Chen et al., 2013) and thereby visualize individual vesicles. Evidence that fluorescent organelles labeled by the latter approach were individual synaptic vesicles include the findings that they matched the diffraction-limited size of $40 \mathrm{~nm}$ fluorescent microspheres; fluorescence of pHrodo-loaded organelles disappeared upon depolarization with rapid kinetics matching exocytosis; and their depolarization-evoked disappearance was blocked by inhibiting $\mathrm{Ca}^{2+}$ channels with $\mathrm{Co}^{2+}$ (Chen et al., 2013). Fusion of individual vesicles can be distinguished from vesicle departure by the much faster decline in fluorescence following vesicle fusion compared to the slower fluorescence changes that accompany vesicle approach or departure from the membrane (Chen et al., 2013). Fusion events were identified by the following criteria: fluorescence must decline by $60 \%$ within two frames $(82 \mathrm{~ms})$ after the peak and exhibit a total decrease of $>90 \%$ (Chen et al., 2013). 


\section{PHOTORECEPTOR ISOLATION}

After loading with pHrodo, retinas were digested by incubation with papain $(30 \mathrm{U} / \mathrm{ml}$, Worthington, Lakewood, NJ, USA) plus cysteine $(0.2 \mathrm{mg} / \mathrm{ml})$ in $\mathrm{Ca}^{2+}$-free amphibian saline solution for $35 \mathrm{~min}$ at $\sim 20^{\circ} \mathrm{C}$. After papain treatment, the tissue was washed in ice cold, $\mathrm{Ca}^{2+}$-free amphibian saline containing $1 \%$ bovine serum albumin and DNase $(1 \mathrm{mg} / \mathrm{ml}$, Worthington) followed by two additional washes in ice-cold, $\mathrm{Ca}^{2+}$-free saline. A piece of retina was then triturated with a fire-polished Pasteur pipette and the cell suspension transferred onto 1.78 refractive index glass cover slips (Olympus, Center Valley, PA, USA) coated with CellTak $\left(3.5 \mu \mathrm{g} / \mathrm{cm}^{2}\right.$, BD Biosciences, San Jose, CA, USA). After letting cells settle and adhere for $30 \mathrm{~min}$, they were superfused with oxygenated amphibian saline solution at $20^{\circ} \mathrm{C}$. Rods were identified by their characteristic morphology. Cones and sometimes bipolar cells were also loaded with pHrodo but not examined in this study. Light-sensitive outer segments of rods were typically lost during trituration.

\section{CALCIUM IMAGING}

$\mathrm{Ca}^{2+}$ channels are clustered beneath ribbons (Nachman-Clewner et al., 1999; Tom Dieck et al., 2005) and so sites of focal $\mathrm{Ca}^{2+}$ entry evoked by brief depolarizing steps co-localize with ribbons labeled with fluorescently tagged Ribeye-binding peptides (Choi et al., 2008; Mercer and Thoreson, 2011; Chen et al., 2013). This allows sites of focal $\mathrm{Ca}^{2+}$ entry to be used as an indication of ribbon location. Ribbons labeled by fluorescently conjugated Ribeyebinding peptides were typically not visible by TIRFM in rods, perhaps because their location atop the arciform density places them outside the evanescent field of illumination (Chen et al., 2013). To image $\mathrm{Ca}^{2+}$ entry sites, fluo- $5 \mathrm{~F}\left(100 \mu \mathrm{M}, K_{\mathrm{d}}=2.3 \mu \mathrm{M}\right.$, Invitrogen) was added to the pipette solution. The sites of peak fluorescence increases evoked by $50-\mathrm{ms}$ depolarizing steps from -70 to $-10 \mathrm{mV}$ with $\Delta F / F>0.5$ were defined as $\mathrm{Ca}^{2+}$ entry sites. Different focal $\mathrm{Ca}^{2+}$ entry sites were defined as separate ribbons if they showed distinct peaks separated by $\geq 500 \mathrm{~nm}$ (Chen et al., 2013).

Endoplasmic reticulum $\mathrm{Ca}^{2+}$ levels are quite high $(60-400 \mu \mathrm{M}$; Michalak et al., 2002). To visualize ER $\mathrm{Ca}^{2+}$ stores, isolated rods were therefore incubated with a low affinity $\mathrm{Ca}^{2+}$ indicator fluo$5 \mathrm{~N} \mathrm{AM}\left(10 \mu \mathrm{M}, K_{\mathrm{d}}=90 \mu \mathrm{M}\right.$, Invitrogen $)$ for $45 \mathrm{~min}$. Cytoplasmic dye was then washed out by obtaining whole cell recordings with $\mathrm{Ca}^{2+}$ - and dye-free pipette solutions (Solovyova and Verkhratsky, 2002).

\section{VISUALIZING pHrodo-LOADED VESICLES AND MONITORING $\mathrm{Ca}^{2+}$ CHANGES BY TIRFM}

561- and 488-nm solid-state lasers (Melles Griot, Carlsbad, CA, USA) were used to illuminate pHrodo-loaded vesicles and $\mathrm{Ca}^{2+}$ indicator dyes, respectively. The beam was focused off-axis onto the back focal plane of a 1.65-NA objective (Apo 100 $\times$ oil, Olympus, Japan). After leaving the objective, light traveled through a high refractive index (1.78) immersion fluid (Cargille Laboratories, Cedar Grove, NJ, USA) and entered the cover slip, undergoing total internal reflection at the interface between the glass and lower refractive index of the cell membrane and overlying aqueous medium. The evanescent wave propagated at this interface declined with a length constant of $64 \mathrm{~nm}$ with the 561$\mathrm{nm}$ laser and $57 \mathrm{~nm}$ with the 488-nm laser (Chen et al., 2013). For pHrodo, fluorescence emission was filtered by $609-\mathrm{nm}(54 \mathrm{~nm}$ wide) bandpass filters (Semrock Inc., Rochester, NY, USA) and collected by an EMCCD camera (Hamamatsu ImagEM, Bridgewater, NJ, USA) at $40 \mathrm{~ms} /$ frame with a pixel size of $80 \mathrm{~nm}$. For $\mathrm{Ca}^{2+}$ imaging with the 488-nm laser, fluorescence emission was filtered by $525-\mathrm{nm}$ ( $45 \mathrm{~nm}$ wide) bandpass filters (Semrock Inc., Rochester, NY, USA) and images were obtained at 14-31 ms/frame. Imaging data were acquired using Metamorph software (Molecular Devices, Sunnyvale, CA, USA) and analyzed with Metamorph and ImageJ 1.46 (NIH, Bethesda, MD, USA).

\section{CELL STIMULATION}

Rods were stimulated by pressure ejection (Toohey Co., Fairfield, NJ, USA) of $50 \mathrm{mM} \mathrm{KCl}$ or $10 \mu \mathrm{M}$ ryanodine from patch pipettes or by application of depolarizing voltage steps to voltage-clamped rods. The tip of the puffer pipette was positioned 10-20 $\mu \mathrm{m}$ away from rod terminals.

For application of depolarizing steps ( -70 to $-10 \mathrm{mV}, 50$ or $500 \mathrm{~ms}$ ), whole cell recordings were obtained from isolated rods, using the rod pipette solution described above. Rods were voltageclamped with an A-M Systems Model 2400 (Carlsborg, WA, USA) amplifier. Currents were acquired and analyzed with pClamp 8 and Digidata 1200 interface (Molecular Devices). Cells with holding currents $>300 \mathrm{pA}$ at $-70 \mathrm{mV}$ were rejected from analysis.

\section{ASSESSING VESICLE MOBILITY FROM FLUORESCENCE CORRELATION MEASUREMENTS}

To test whether CICR increased vesicle mobility in rod terminals, we loaded a small fraction of vesicles with pHrodo and then examined rod terminals under epifluorescent illumination. We focused the microscope on the cytoplasm above the membrane to avoid possible effects of release on measured changes in fluorescence. Ryanodine $(10 \mu \mathrm{M})$ was puffed onto rod terminals to activate CICR. We compared the average frame-to-frame correlations in intraterminal fluorescence among 23 frames in the resting state to the average correlations in the CICR-activated state during the puff.

\section{FLUORESCENCE RECOVERY AFTER PHOTOBLEACHING}

The ER of isolated rods was labeled by incubation with $1 \mu \mathrm{M}$ ER-tracker green (Invitrogen) for $30 \mathrm{~min}$ at $20^{\circ} \mathrm{C}$. Terminals of rods were photobleached for $5 \mathrm{~s}$ by illumination with a small spot (8 $\mu \mathrm{m}$ diameter) from a 30-mW 488-nm laser. ER-tracker green was illuminated by epifluorescence and images were acquired every $3 \mathrm{~s}$. To show that ER-tracker dye labeled intracellular structures, we also visualized rods using a spinning disk confocal microscope (PerkinElmer Ultraview LCI).

\section{STATISTICAL ANALYSIS}

Statistical analysis was performed with GraphPad Prism 4 (La Jolla, CA, USA). Unless otherwise stated, results are presented as mean \pm SEM and statistical significance was determined using Student's $t$ test. The criterion for statistical significance was chosen to be $p<0.05$. 


\section{RESULTS}

\section{DAMAGING RIBBONS BLOCKED FAST BUT NOT SLOW RELEASE FROM} RODS

By using capacitance measurements of exocytosis in rods, we found previously that damaging the ribbon protein Ribeye by FALI significantly inhibited release evoked by short 50-ms depolarizing steps but did not significantly inhibit slow release evoked by longer 200-ms depolarizing steps (Chen et al., 2013). This suggests that ribbon release contributes to fast but not slow release from rods. To further assess the contribution of ribbons to slow release from rods, we studied the effects of damaging ribbons by FALI on glutamatergic excitatory post-synaptic currents (EPSCs) evoked in horizontal cells by depolarizing steps applied to simultaneously voltage-clamped rods ( -70 to $-10 \mathrm{mV}, 200 \mathrm{~ms}$; Figure 1A). For FALI, we used a fluorescein-conjugated peptide that binds selectively to the B domain of Ribeye (Zenisek et al., 2004). The peptide $(80 \mu \mathrm{M})$ was introduced into rods through patch pipettes and then bleached with a 488-nm Ar/Kr laser for 50 s to cause highly localized damage to the ribbon (Snellman et al., 2011). Depolarization of rods with a short test step evokes a fast, transient EPSC ( Li et al., 2010) and additional slower components are evoked by longer steps (Thoreson, 2007). Consistent with the initial fast component involving release from ribbons, we found that the amplitude of the initial fast component of the EPSC observed within the first $10 \mathrm{~ms}$ of the step (Figure 1B) was reduced by damaging the ribbon but slower components of the EPSC were not. The post-FALI response shown in Figures 1A,B is the third response after bleaching. The first response obtained after FALI was not diminished, consistent with results from bipolar cells and cones indicating that release of vesicles that were previously primed and attached to the ribbon was not impaired by ribbon damage (Snellman et al., 2011). As illustrated in Figure 1C, the fast EPSC component was reduced $49 \pm 9 \%(n=10, p=0.0052)$ by the fourth test step after FALI. Bleaching a scrambled control version of the peptide conjugated to fluorescein did not reduce EPSCs ( $n=5, p=0.8923$; Figure 1C).

By contrast with the reduction in fast release, damaging the ribbon by FALI did not inhibit slow release (Figure 1A). Comparing the charge transfer of control EPSCs to EPSCs after FALI (average of third through sixth responses), EPSCs were reduced by only $2 \pm 11 \%(n=9, p=0.9342)$. Assuming that the $49 \%$ decline in the amplitude of the fast EPSC component means that half of the ribbon sites were damaged by FALI, this suggests that release from

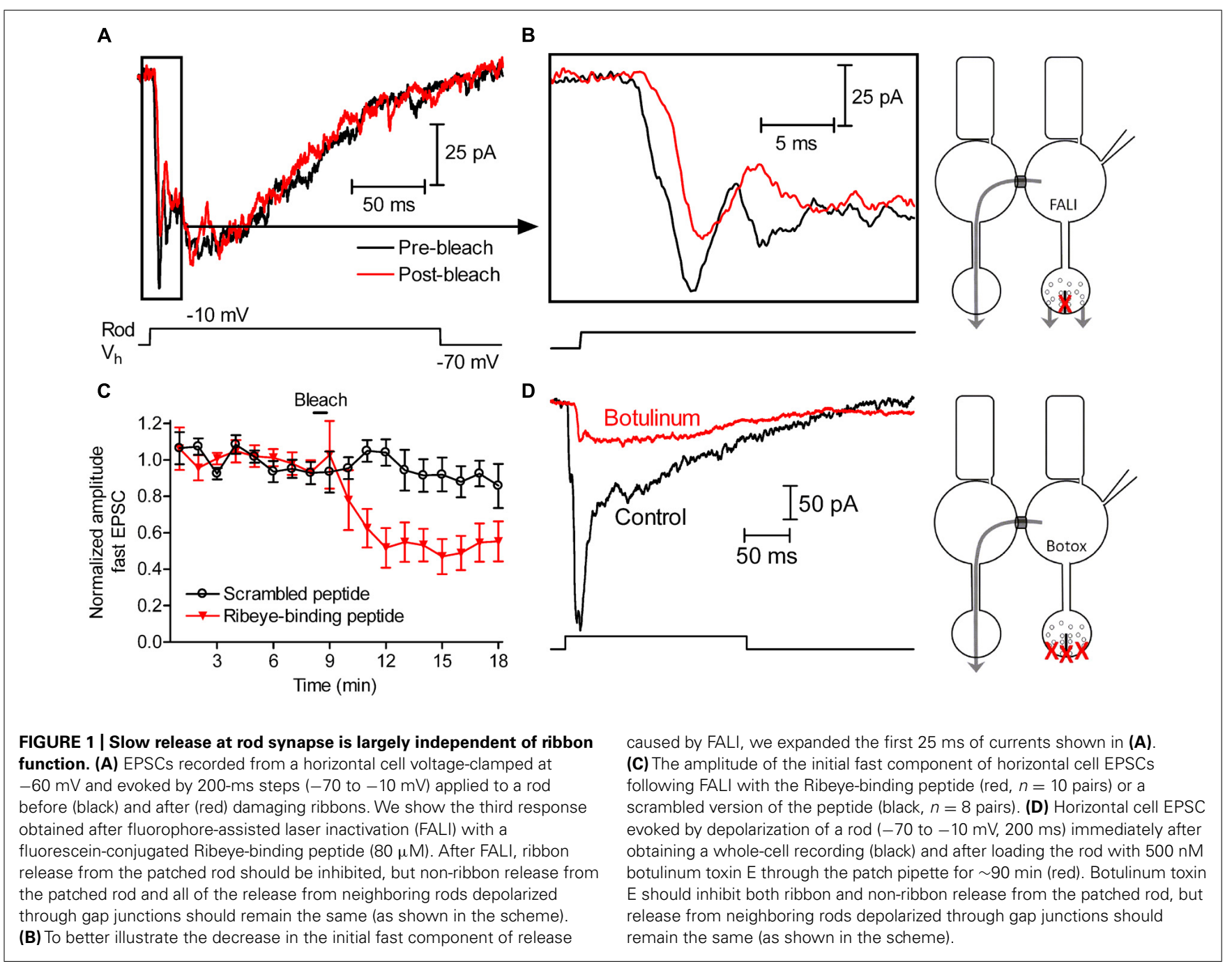


ribbons contributes only $\sim 4 \%$ to the total EPSC charge transfer evoked by a $200-\mathrm{ms}$ step to $-10 \mathrm{mV}$.

Both staining of connexin 35/36 immunofluorescence and the ultrastructure revealed by electron microscopy show that rods in tiger salamander retina are connected to one another by gap junctions found on fin-like extensions from their somas (Zhang and Wu, 2004). Depolarizing current injected into a voltage-clamped rod can spread through these gap junctions into neighboring rods (Attwell et al., 1984; Zhang and Wu, 2005) allowing release from neighboring rods to contribute to rod-driven EPSCs (Cadetti et al., 2005). The gap junction inhibitor carbenoxolone reduced slow components of rod-driven EPSCs but causes incomplete inhibition of rod-rod coupling (Cadetti et al., 2005) and also inhibits L-type $I_{\mathrm{Ca}}$ (Vessey et al., 2004). Therefore, to measure contributions from rod-rod coupling to depolarization-evoked EPSCs, we used an alternate strategy of introducing botulinum toxin type E light chain (500 nM; R\&D Systems, Minneapolis, MN, USA) into rods through the patch pipette. Botulinum toxin $\mathrm{E}$ cleaves the SNARE protein SNAP-25 that is expressed in photoreceptors (Ramakrishnan et al., 2012). Introduction of botulinum toxin E should therefore block vesicle fusion in the voltage-clamped rod but leave release from coupled rods unaffected (Figure 1D). After recording for more than an hour from rod-horizontal cell pairs with botulinum toxin in the presynaptic patch pipette, the total EPSC charge transfer was reduced by $56 \pm 14 \%(n=5$, $p=0.0161)$. The portion that remained $(43 \%)$ could involve SNARE-independent release (Nouvian et al., 2011) but was more likely due to spread of current into neighboring rods since this residual current was reduced another $68 \pm 4 \%(n=4, p=0.0005)$ by hyperpolarizing neighboring rods with bright light. These results suggest that $56 \%$ of the EPSC was due to release from the voltage-clamped rod. Together with FALI results suggesting that $4 \%$ of the EPSC was due to release at ribbons, this suggests that $\sim 7 \%$ (4\%/56\%) of release from voltage-clamped rods evoked by $200-\mathrm{ms}$ steps to $-10 \mathrm{mV}$ occurred at ribbons. This supports the conclusion of other studies suggesting that rods are capable of considerable non-ribbon release (Zampighi et al., 2011; Chen et al., 2013).

\section{SUSTAINED DEPOLARIZATION RELEASES $\mathrm{Ca}^{2+}$ FROM INTRACELLULAR STORES IN ROD TERMINALS}

Consistent with previous work showing that the machinery for CICR is present in rod terminals (Križaj et al., 1999, 2003; Cadetti et al., 2006), we found that activating ryanodine receptors on ER by puffing a low concentration of ryanodine $(10 \mu \mathrm{M})$ increased submembrane $\left[\mathrm{Ca}^{2+}\right]_{\mathrm{i}}$ throughout rod terminals as measured by TIRFM using the $\mathrm{Ca}^{2+}$-sensitive dye, fluo-5F (Figures 2A,B; $n=7$ ). Figure $2 \mathrm{E}$ shows the increase in fluo-5F fluorescence evoked by ryanodine puff measured within a region of interest in the rod terminal. After emptying $\mathrm{ER} \mathrm{Ca}^{2+}$ stores by application of a sarcoplasmic/ER $\mathrm{Ca}^{2+}$-ATPase (SERCA) inhibitor, cyclopiazonic acid (CPA; $5 \mu \mathrm{M})$, ryanodine failed to stimulate an increase in $\left[\mathrm{Ca}^{2+}\right]_{\mathrm{i}}$ (Figures 2C-E, filled circles; $n=18$ ). Ryanodine-evoked CICR was also blocked by pretreatment with another SERCA inhibitor, thapsigargin ( $1 \mu \mathrm{M} ; n=13$; not shown).

We examined the sources of $\mathrm{Ca}^{2+}$ involved in depolarizationevoked increases in submembrane $\left[\mathrm{Ca}^{2+}\right]_{\mathrm{i}}$. Consistent with earlier

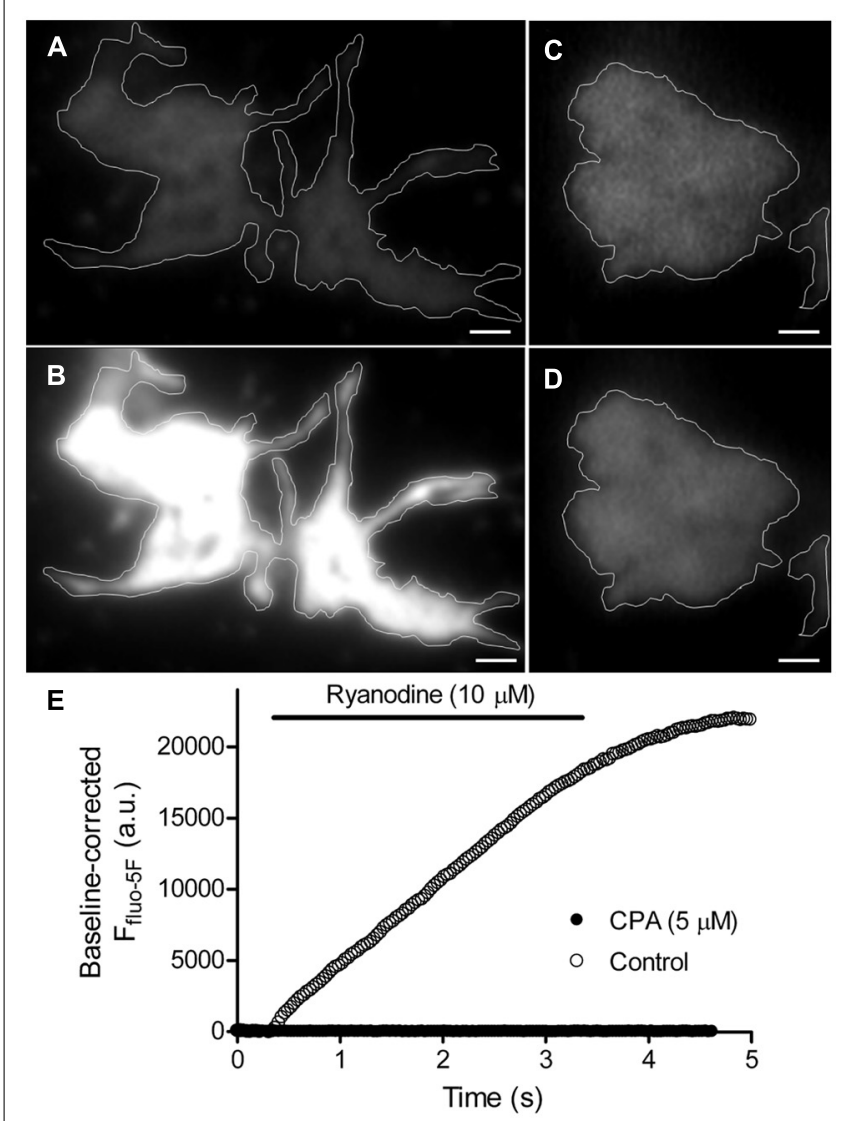

FIGURE $2 \mid \mathrm{Ca}^{2+}$-induced $\mathrm{Ca}^{2+}$ release (CICR) occurs near plasma membrane in rod terminals. Panels $(\mathbf{A}, \mathbf{C})$ show average images of the footprints of two rod terminals loaded with fluo-5F (averaged from 19 frames and 9 frames, respectively; $31 \mathrm{~ms} /$ frame). Rods were stimulated by puff application of the ryanodine receptor agonist, $10 \mu \mathrm{M}$ ryanodine, for $3 \mathrm{~s}$. In control conditions, activation of $\mathrm{CICR}$ with ryanodine stimulated large increase in submembrane $\mathrm{Ca}^{2+}$ throughout the terminal $(\mathbf{B}$; average of 33 images). After inhibiting the sarcoplasmic/endoplasmic reticulum ATPase (SERCA) by bath application of $5 \mu \mathrm{M}$ cyclopiazonic acid (CPA), ryanodine puff failed to stimulate a $\mathrm{Ca}^{2+}$ increase ( $\mathbf{D}$; average of 29 frames). The changes in fluo-5F fluorescence intensity measured within these two terminals are plotted in (E). Scale bar: $1 \mu \mathrm{m}$.

findings (Cadetti et al., 2006; Chen et al., 2013), 50-ms depolarizing steps $(-70$ to $-10 \mathrm{mV})$ triggered spatially confined $\mathrm{Ca}^{2+}$ increases (Figure 3A, top row), reflecting the clustering of $\mathrm{Ca}^{2+}$ channels adjacent to ribbons (Nachman-Clewner et al., 1999; Tom Dieck et al., 2005). Longer 500-ms steps triggered $\mathrm{Ca}^{2+}$ increases that spread throughout the terminal (Figure 3A, bottom row). Blocking ryanodine receptors by addition of a ryanodine receptor blocker, dantrolene $(30 \mu \mathrm{M}$, Figure 3B), or a high concentration of ryanodine ( $100 \mu \mathrm{M}$, not shown) to the pipette solution did not affect $\mathrm{Ca}^{2+}$ influx evoked by 50-ms steps (Figure 3B, left), but confined the spread of $\mathrm{Ca}^{2+}$ evoked by 500 -ms depolarizing steps as expected from a block of CICR (Figure 3B, right). The time course for $\mathrm{Ca}^{2+}$ changes in two regions of interest (Figures 3C,D), placed over a focal $\mathrm{Ca}^{2+}$ entry site (region 1; Figure 3B) and away from focal $\mathrm{Ca}^{2+}$ entry sites (region 2; Figure 3B), further confirmed the effectiveness of the ryanodine receptor-mediated block of CICR 


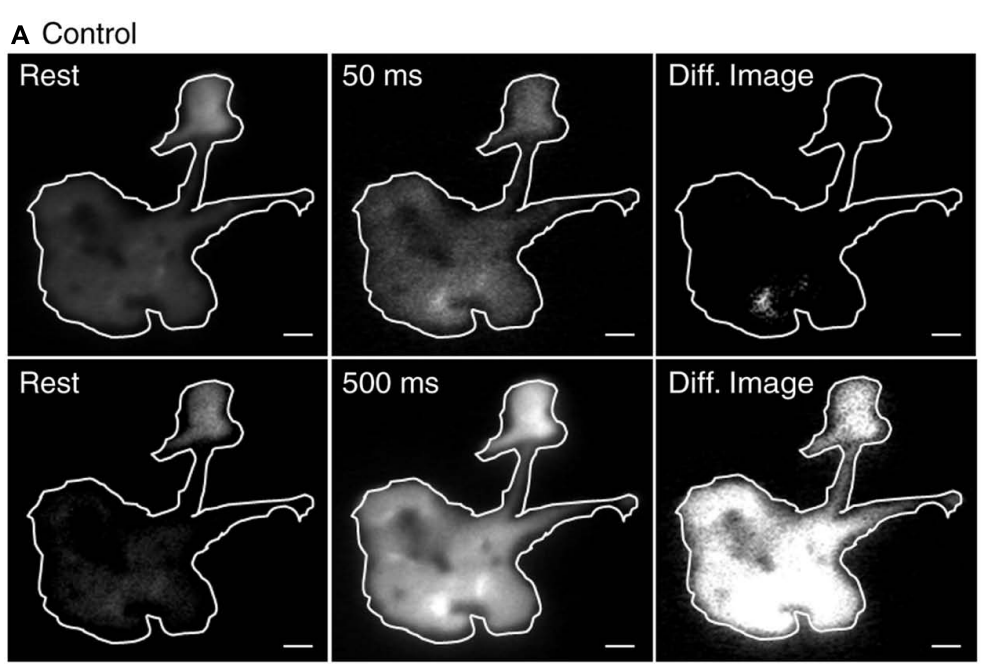

B Dantrolene $(30 \mu \mathrm{M})$
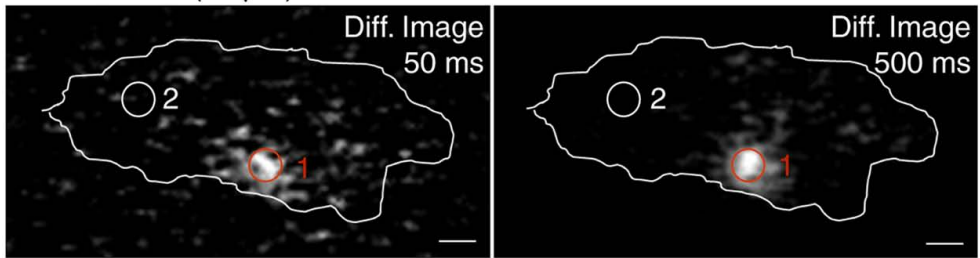

C
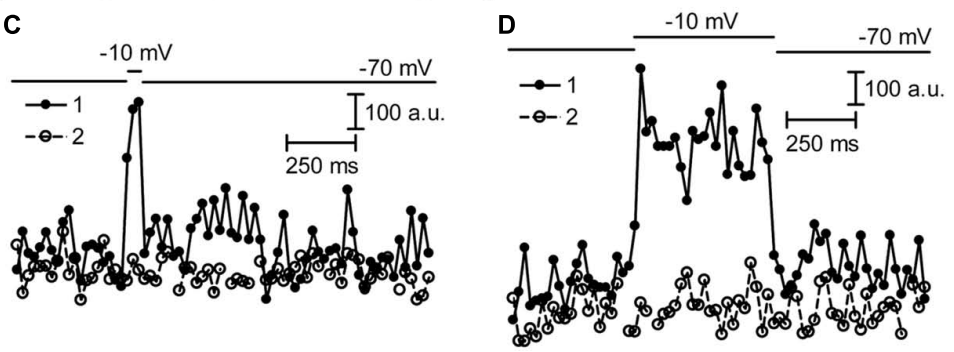

FIGURE 3 | Spread of submembrane $\mathrm{Ca}^{2+}$ during sustained depolarization is due to CICR. Rods were loaded with fluo-5F (100 $\mu \mathrm{M})$ through a patch pipette $(\mathbf{A}, \mathbf{B})$. Submembrane $\left[\mathrm{Ca}^{2+}\right]_{i}$ changes were monitored using a 488-nm laser under TIRFM at $21.3 \mathrm{~ms} /$ frame (A,B). (A,B) Rods were voltage clamped and depolarized from -70 to $-10 \mathrm{mV}$ for 50 or $500 \mathrm{~ms}$. Resting images were obtained by averaging 19 images before depolarization. Depolarized images were obtained by selecting one frame during 50-ms steps or by averaging 21 image frames during 500-ms steps. Difference images were generated by subtracting the resting images from the images during depolarization. The rod in (A) shows that a 50-ms depolarizing step applied under control conditions stimulated localized

during sustained depolarization. After blocking CICR, depolarization with a 500-ms step evoked a localized $\mathrm{Ca}^{2+}$ increase in region 1 near the presumed location of a ribbon but evinced little change in other parts of the terminal (e.g., region 2). Thus, blocking CICR converted the $\left[\mathrm{Ca}^{2+}\right]_{i}$ response evoked by a sustained depolarization to a confined response typically observed following brief depolarizing steps.

Similar to these voltage-clamp experiments, depolarization evoked by puffing high $\mathrm{KCl}$ solutions $(50 \mathrm{mM} \mathrm{KCl} ; 500 \mathrm{~ms}$ to $1 \mathrm{~s})$ increased $\left[\mathrm{Ca}^{2+}\right]_{i}$ throughout the terminal and this spread of $\mathrm{Ca}^{2+}$ was confined by blocking CICR with dantrolene $(10 \mu \mathrm{M}$, not shown). These findings show that the spread of submembrane submembrane $\mathrm{Ca}^{2}+$ increases in the terminal, but a 500-ms step applied under the same conditions stimulated submembrane $\mathrm{Ca}^{2+}$ increases throughout the terminal. Difference images in $(\mathbf{B})$ were generated by subtracting the resting image (average of 19 frames) before stimulation from the test image obtained during stimulation with a 50-ms step (one frame) or a $500-m s$ step (average of 23 frames) in the same terminal. The difference images show that $\mathrm{Ca}^{2}+$ increases evoked by 500 -ms steps were confined after $\mathrm{CICR}$ was inhibited with a ryanodine receptor blocker, dantrolene $(30 \mu \mathrm{M})$ in the patch pipette. Changes in fluo-5F fluorescence intensities within region 1 (red circles) and region 2 (white circles) were plotted against time for both 50-ms (C) and 500-ms steps (D). Scale bar: $1 \mu \mathrm{m}$.
$\mathrm{Ca}^{2+}$ during sustained depolarization is due to CICR, consistent with previous studies (Križaj et al., 1999, 2003; Cadetti et al., 2006; Babai et al., 2010b).

\section{$\mathrm{Ca}^{2+}$ RELEASED FROM INTRACELLULAR STORES TRIGGERS SYNAPTIC VESICLE RELEASE}

The finding that $\mathrm{Ca}^{2+}$ released from ER can attain high levels just beneath the membrane suggests that CICR may be able to stimulate synaptic vesicle release. To visualize CICR-mediated individual synaptic vesicle release, we loaded a small percentage of synaptic vesicles in rod terminals with dextran-conjugated pHrodo (Chen et al., 2013) and transiently exposed them to an agonist 
concentration of ryanodine $(10 \mu \mathrm{M})$. During ryanodine puffs, fluorescently labeled vesicles brightened as they approached the membrane and disappeared rapidly as they fused (Figures 4A,B). By counting the number of release events at each time point, we found that vesicle release increased during stimulation of CICR with ryanodine $(10 \mu \mathrm{M}$, Figure $4 \mathrm{C}) . \mathrm{Co}^{2+}(1 \mathrm{mM})$ in a nominally $\mathrm{Ca}^{2+}$-free solution did not inhibit ryanodine-evoked release (Figure 4D) although this same condition blocked release evoked by puff application of $50 \mathrm{mM} \mathrm{KCl}$ (Chen et al., 2013). However, co-application of dantrolene $(10 \mu \mathrm{M}$, Figure $4 \mathrm{E})$ inhibited vesicle release during ryanodine puffs. Thus, CICR can trigger release even when voltage-operated $\mathrm{Ca}^{2+}$ channels are blocked.

At Drosophila neuromuscular junction, CICR enhances release by increasing vesicle mobility (Shakiryanova et al., 2005). To test whether CICR increased vesicle mobility in rod terminals, we puffed ryanodine $(10 \mu \mathrm{M})$ onto terminals and analyzed frameto-frame fluorescence correlations to assess changes in vesicle mobility. We focused on cytoplasmic vesicles in the center of the terminal illuminated by epifluorescence, not TIRFM. Activation of CICR did not alter fluorescence correlations indicating that CICR did not alter vesicle mobility (correlation coefficients at rest $=0.910$ and during ryanodine puff application $=0.907, n=8$, $p=0.47$, paired $t$-test). This is consistent with results of fluorescence recovery after photobleach (FRAP) experiments showing that unlike conventional synapses where most vesicles are tethered to actin via synapsin (Benfenati et al., 1989), vesicles in ribbon synapses are largely mobile and their mobility is unaffected by $\left[\mathrm{Ca}^{2+}\right]_{\mathrm{i}}$ (Holt et al., 2004; Rea et al., 2004; Chen et al., 2013).

\section{CICR EVOKED NON-RIBBON RELEASE DURING SUSTAINED DEPOLARIZATION}

To investigate the spatial distribution of release events triggered by $\mathrm{Ca}^{2+}$ from intracellular stores, we mapped individual vesicle release events. Focal $\mathrm{Ca}^{2+}$ entry sites visualized during $50-\mathrm{ms}$ depolarizing steps (Figure 3A) were used to identify ribbon locations. The distance from the nearest $\mathrm{Ca}^{2+}$ entry site was measured for each release event. Previously (Chen et al., 2013), we found that 500-ms steps evoked greater non-ribbon release than 50-ms steps.

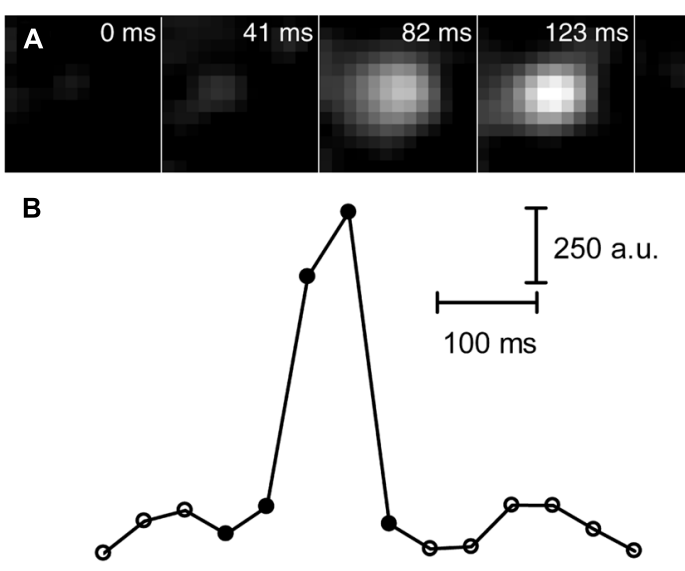

D

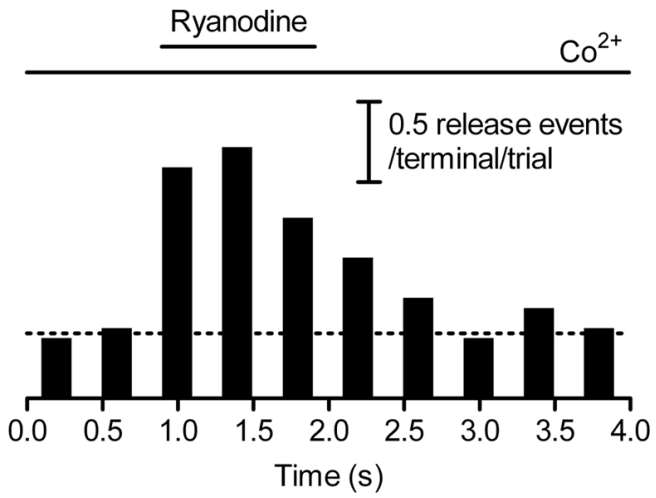

FIGURE $4 \mid \mathrm{Ca}^{2+}$ released from intracellular stores is capable of triggering release. (A) Sequential images show a pHrodo-loaded vesicle brightening as it approached the membrane and then disappearing due to fusion, following stimulation with a puff of ryanodine $(10 \mu \mathrm{M})$. Scale bar: $500 \mathrm{~nm}$. (B) Changes in fluorescence intensity within a 560-nm diameter region of interest placed over this vesicle are plotted against time in (B). Filled circles indicate the fluorescence intensities of the five frames shown in (A). To plot release kinetics in panels (C-E), we counted the number of synaptic vesicle release events per rod terminal

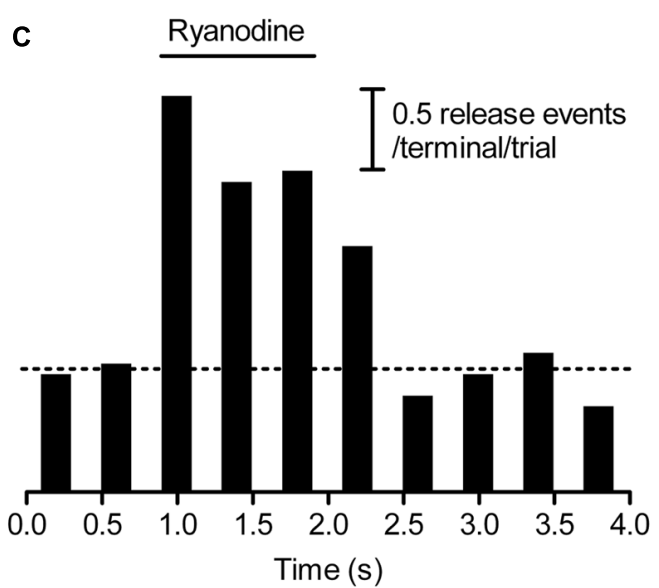

E

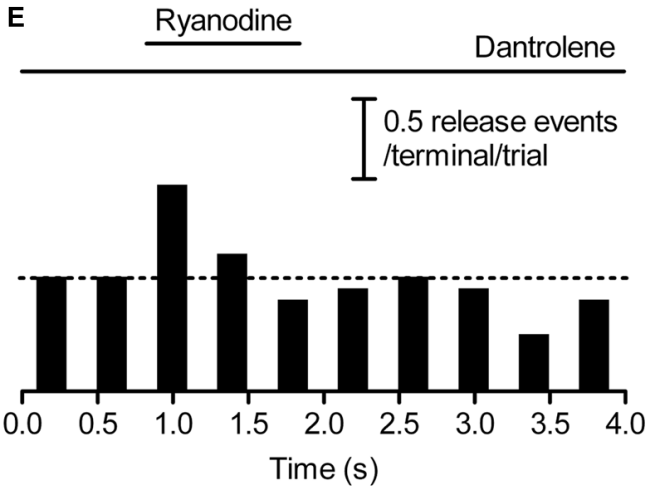

per trial, binned events in 40-ms increments, and plotted them against time. (C) In control conditions, the number of release events increased during puff application of ryanodine (10 $\mu \mathrm{M} ; n=15$ rods). (D) Ryanodine (10 $\mu \mathrm{M} ; n=16$ rods) stimulated an increase in release when rods were superfused with $\mathrm{Ca}^{2+}$-free Ringer's solution containing $\mathrm{Co}^{2+}$ (1 $\mathrm{mM}, n=16$ rods). (E) Ryanodine (10 $\mu \mathrm{M} ; n=14$ rods) caused little increase in release in the presence of a ryanodine receptor blocker, dantrolene $(10 \mu \mathrm{M})$. The dashed line in (C-E) shows the level of release before ryanodine puff. 
To test whether additional non-ribbon release during 500-ms steps was due to CICR-mediated spread of $\mathrm{Ca}^{2+}$ throughout the terminal, we included dantrolene $(30 \mu \mathrm{M})$ in the pipette solution. As described above, inclusion of dantrolene blocked CICR and resulted in a confined $\left[\mathrm{Ca}^{2+}\right]$ increase during 500-ms steps that resembled confined $\left[\mathrm{Ca}^{2+}\right]$ increases triggered by 50 -ms depolarizing steps (Figure 3B). Dantrolene also confined release events evoked by 500-ms steps close to focal $\mathrm{Ca}^{2+}$ entry sites (Figure 5). In the presence of dantrolene, most $(\sim 75 \%)$ of the release events evoked by 500 -ms steps occurred within $1 \mu \mathrm{m}$ of the focal $\mathrm{Ca}^{2+}$ entry sites, matching the distribution of release events evoked by 50-ms steps in the presence or absence of dantrolene (Figure 5). For comparison, salamander rod ribbons average $\sim 1 \mu \mathrm{m}$ in length (Townes-Anderson et al., 1985). Data from Chen et al. (2013) were re-plotted in Figure 5 (dashed red line) and show that 500-ms steps applied in control conditions evoked a significantly larger number of release events than $50 \mathrm{~ms}$ steps ( $\sim 50 \%$, KolmogorovSmirnov test: $p=0.019)>1 \mu \mathrm{m}$ from the ribbon. Consistent with electrophysiological results showing the contribution of CICR to slow release (Cadetti et al., 2006; Suryanarayanan and Slaughter, 2006), dantrolene also strongly inhibited slower components of release evoked by 500-ms steps measured optically (data not shown). These results indicate that virtually all of the additional non-ribbon release evoked by sustained depolarization is due to CICR.

To observe the behavior of a large number of vesicles, we incubated rods with pHrodo for $30 \mathrm{~min}$. We mapped sites of vesicle recruitment and subsequent release from increases in nearmembrane fluorescence that accompanied membrane approach of vesicles just prior to fusion. Since $85 \%$ of near-membrane vesicles subsequently fuse, recruitment maps provide a good map of release sites (Chen et al., 2013). CICR was activated by ryanodine $(10 \mu \mathrm{M})$ puff application. Recruitment maps were generated by subtracting the average control image from the average stimulated image obtained during ryanodine puff. A representative recruitment map is shown in Figure 6A. To map ribbon locations, we voltage-clamped these rods and loaded them with fluo-5F to visualize focal sites of $\mathrm{Ca}^{2+}$ entry evoked by depolarization with $50-\mathrm{ms}$ steps (e.g., Figure 6B). As illustrated by overlay of a vesicle recruitment map (red) and ribbon locations (green) in Figure 6C, the sites to which vesicles were recruited by activation of CICR did not overlap with ribbons in five out of six rods. In one rod, there was partial overlap. Given that release-ready vesicles are thought to cluster primarily at ribbons, it was surprising to find that direct stimulation of CICR stimulated recruitment and subsequent release almost exclusively at non-ribbon sites. However, the finding that CICR triggers release almost entirely at non-ribbon sites complements the previous finding that non-ribbon release during sustained depolarization is almost entirely due to CICR.

We also compared the location of release sites evoked by activation of CICR with ryanodine $(10 \mu \mathrm{M})$ to those evoked by depolarizing stimulation with $50 \mathrm{mM} \mathrm{KCl}$ in the same terminals. Recruitment maps were generated in terminals loaded by 30 -min incubation with pHrodo as described above. Vesicle recruitment triggered by puff application of $50 \mathrm{mM} \mathrm{KCl}$ was concentrated at a few sites in each terminal with some additional recruitment observed elsewhere in the terminal (Figure 7A). The clustering of

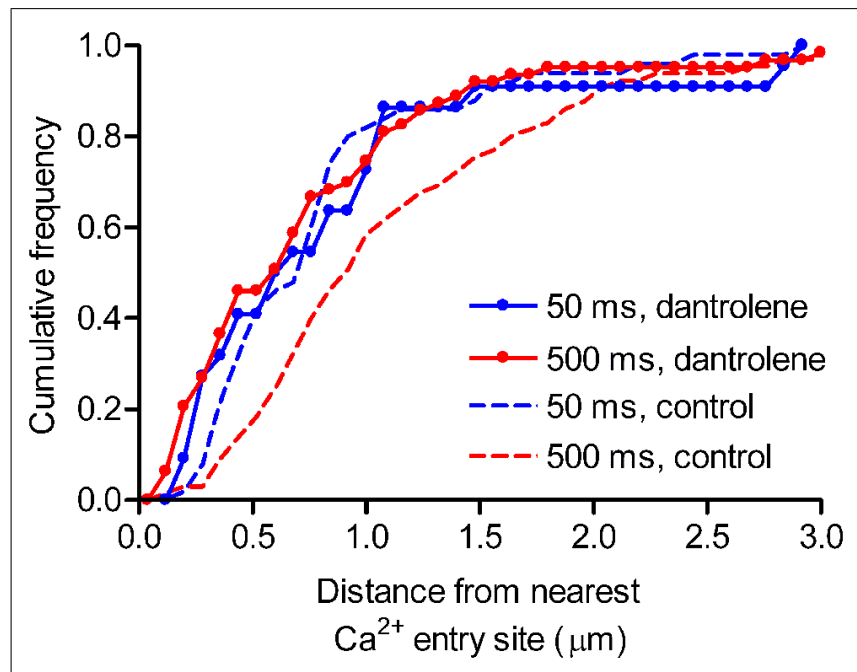

FIGURE 5 | Inhibiting CICR with dantrolene decreased non-ribbon release. Rods were loaded with pHrodo to label synaptic vesicles and then voltage clamped. Fluo-5F (100 $\mu \mathrm{M})$ and dantrolene $(30 \mu \mathrm{M})$ were introduced through the patch pipette. Rods were stimulated with 50- or $500-\mathrm{ms}$ steps from -70 to $-10 \mathrm{mV}$. The relative cumulative frequencies of pHrodo-loaded vesicle release events stimulated by 50- (blue circles, $n=22$ events from nine rods) or 500-ms (red circles, $n=63$ events from nine rods) steps plotted against distance from the nearest $\mathrm{Ca}^{2+}$ entry site. For comparison, the cumulative frequencies of release events obtained under control conditions without dantrolene are replotted from Chen et al. (2013) for 50- (blue dashed line) and 500-ms (red dashed line) steps. When $\mathrm{CICR}$ was inhibited with dantrolene, release events triggered by $500-\mathrm{ms}$ steps clustered close to $\mathrm{Ca}^{2+}$ entry sites, matching the distribution seen with release evoked by $50-\mathrm{ms}$ steps [Kolmogorov-Smirnov (K-S) test: $p=0.936$ ]. By contrast, the distribution of release events evoked by $500-m s$ steps in control conditions differed significantly from the distribution of release events evoked by 500-ms steps in the presence of dantrolene (K-S test: $p=0.002$ ). Scale bar: $1 \mu \mathrm{m}$.

newly recruited vesicles observed during depolarizing stimulation co-localizes with synaptic ribbons (Chen et al., 2013). These results suggest that depolarizing stimulation with a high concentration of $\mathrm{K}^{+}$triggers ribbon release as well as some additional release at non-ribbon sites. Ribbon release was presumably triggered by $\mathrm{Ca}^{2+}$ influx through $\mathrm{Ca}^{2+}$ channels clustered near the ribbon whereas non-ribbon release was due to the secondary activation of CICR.

Release of $\mathrm{Ca}^{2+}$ from intracellular stores evoked by puff application of ryanodine $(10 \mu \mathrm{M})$ stimulated vesicle recruitment and release at more diffusely distributed locations throughout the terminal than high $\mathrm{K}^{+}$stimulation (Figure 7B). Furthermore, sites of vesicle recruitment triggered by activation of CICR with ryanodine differed from sites of vesicle recruitment and release triggered by depolarizing stimulation with $50 \mathrm{mM} \mathrm{KCl}$ (Figure 7C; $n=5$ rods). Because depolarizing stimulation preferentially stimulated release from ribbon sites, this provides further evidence that CICR preferentially stimulates release at non-ribbon sites.

To test whether non-ribbon release occurs at fixed locations, we repeatedly stimulated CICR in rod terminals with puff application of ryanodine. We also tested repeated stimulation by puff application of high $\mathrm{KCl}$ solutions. To keep cells healthy and improve responses to repeated stimulation, the stimulus strength 

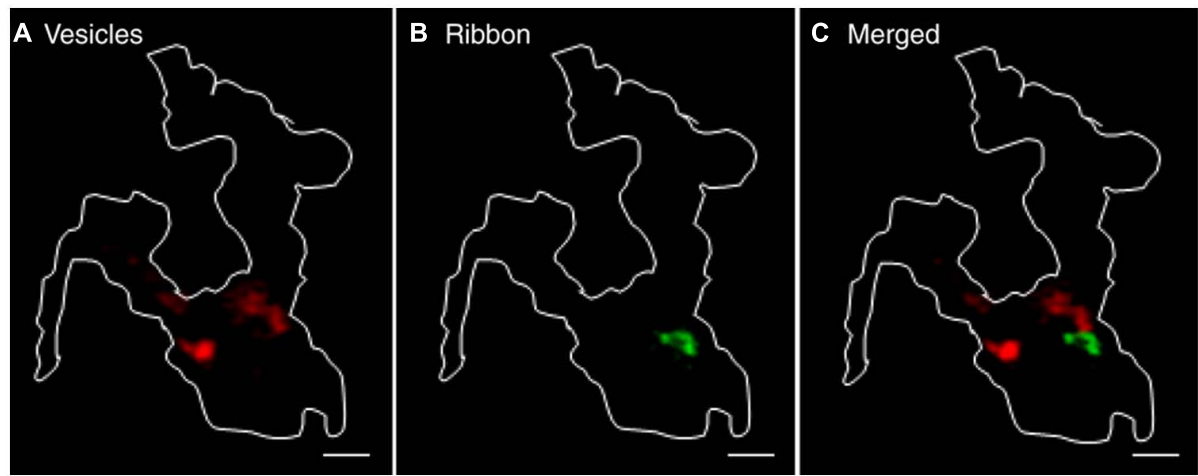

FIGURE $6 \mid \mathrm{Ca}^{2+}$ released from intracellular stores evokes non-ribbon release. A large number of synaptic vesicles in rods were loaded with pHrodo by 30-min incubation. Rods were voltage clamped and loaded with fluo-5F through the pipette. (A) Vesicle recruitment map in a rod terminal that was puffed with $10 \mu \mathrm{M}$ ryanodine. The map was generated by subtracting the average of 37 resting images before puff from the average of 52 test images during puff. (B) $\mathrm{Ca}^{2+}$ entry sites visualized by depolarizing the same rods with a 50-ms step from -70 to $-10 \mathrm{mV}$ to trigger influx through $\mathrm{Ca}^{2+}$ channels clustered near ribbons. The difference image was generated by subtracting the average of 15 resting images before the step from an average of two test images during the 50-ms depolarizing test step. The overlaid image in (C) shows that sites of vesicle recruitment and release did not overlap with locations of ribbons shown by focal $\mathrm{Ca}^{2+}$ entry sites. Scale bar: $1 \mu \mathrm{m}$.

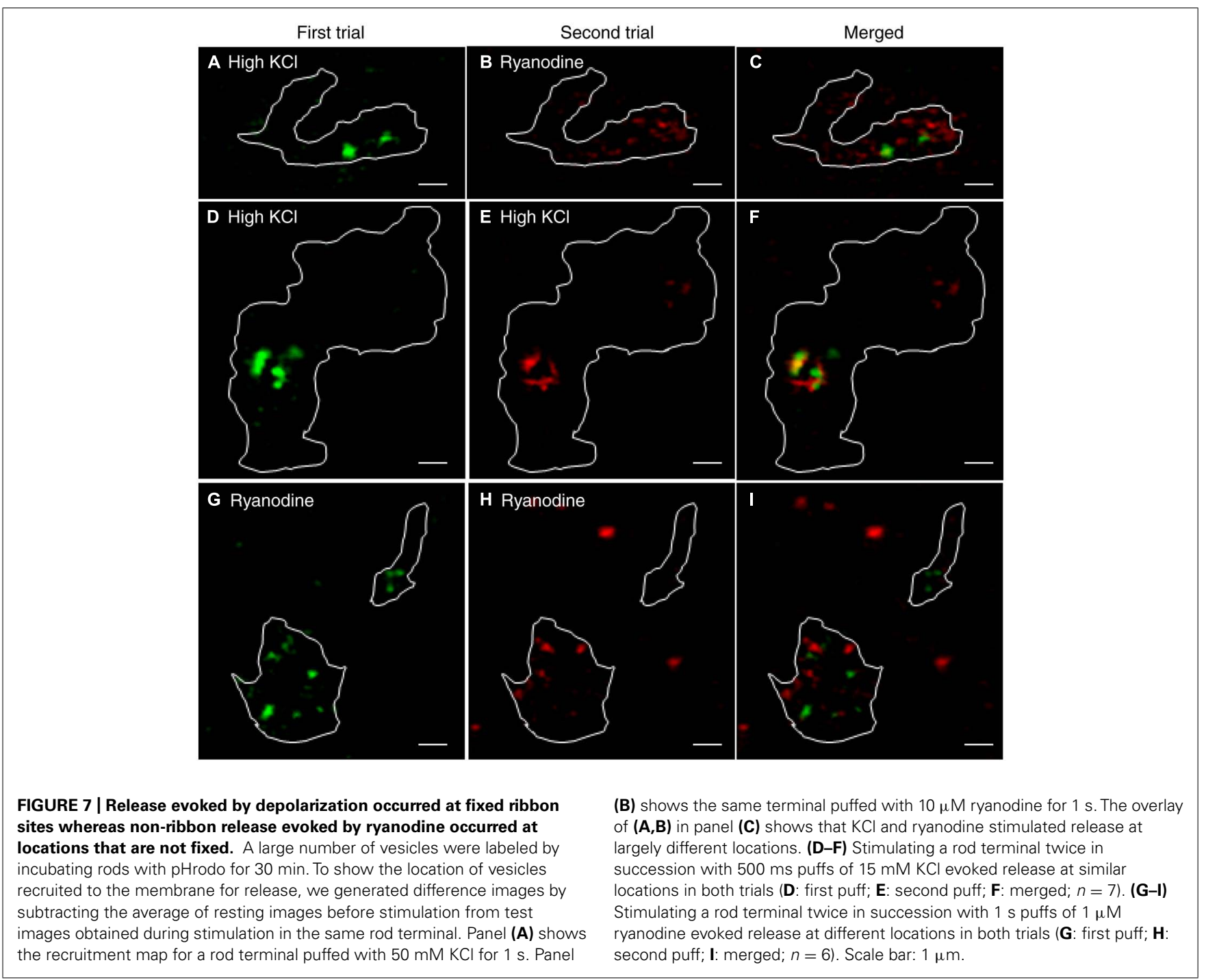


was reduced ( $1 \mu \mathrm{M}$ ryanodine puff for $1 \mathrm{~s}$ to activate CICR; $15 \mathrm{mM}$ $\mathrm{KCl}$ for $500 \mathrm{~ms}$ as a depolarizing stimulus). Puff application of $\mathrm{KCl}$ twice in succession triggered vesicle recruitment and release concentrated at overlapping locations in both trials although there was also some vesicle recruitment to other sites (Figures 7D-F; $n=7$ rods). Vesicle recruitment at these additional sites may be due to activation of CICR by KCl puffs. By contrast with the largely repeatable sites evoked by $\mathrm{KCl}$ puffs, two successive puffs of ryanodine triggered vesicle recruitment and release at different sites in the two trials (Figures 7G-I; $n=6$ rods). These results suggest that depolarization-evoked release at ribbons occurs at fixed locations whereas sites of non-ribbon release triggered by CICR are not fixed.

\section{$\mathrm{Ca}^{2+}$ CAN DIFFUSE THROUGH CONTINUOUS ER EXTENDING FROM SOMA TO TERMINAL}

If sustained release requires CICR, then $\mathrm{ER} \mathrm{Ca}^{2+}$ stores must be capable of maintaining CICR during sustained depolarization. Consistent with this, we found that submembrane $\mathrm{Ca}^{2+}$ levels remained elevated throughout rod terminals when depolarized by $15 \mathrm{mM} \mathrm{KCl}$ for $10 \mathrm{~s}(n=9)$. Furthermore, evidence that blocking CICR inhibits light responses in second-order neurons and ongoing glutamate release from rods suggests that CICR can be maintained almost indefinitely (Cadetti et al., 2006; Suryanarayanan and Slaughter, 2006; Babai et al., 2010b). These results prompted us to ask how CICR can be maintained for long periods of time.

Ultrastructural studies of photoreceptors show the presence of ER in the terminal, axon, and soma (Mercurio and Holtzman, 1982). In other polarized cells, ER forms a continuous network throughout the cell allowing $\mathrm{Ca}^{2+}$ ions to tunnel through ER from one region to another (Mogami etal., 1997; Choi et al., 2006; Petersen and Verkhratsky, 2007). We hypothesized that the ER network in rods may form a continuous network allowing $\mathrm{Ca}^{2+}$ to diffuse from soma to terminal ER in support of sustained synaptic release. To test whether ER in rods forms a continuous structure extending from terminal to soma, we labeled ER with the dye ER-tracker green, which binds to sulphonylurea receptors of ATP-sensitive $\mathrm{K}^{+}$channels that are prominent on ER (Hambrock et al., 2002). Confocal images of isolated rods labeled with ER-tracker green showed fluorescent labeling of intracellular structures, presumably ER, throughout the soma and terminal (Figure 8A). To test for continuity of these labeled structures, we measured recovery of terminal fluorescence after photobleaching ER-tracker green with a laser spot $(488 \mathrm{~nm}, 30 \mathrm{~mW}, 8 \mu \mathrm{m}$ in diameter) centered on the terminal. We monitored cell fluorescence at $3 \mathrm{~s}$ intervals before and after laser photobleaching (Figure 8B). By measuring the rate of fluorescence decline in terminals and somas of control cells from the same microscope field that were not photobleached by the laser, we determined that epifluorescent measurements made every $3 \mathrm{~s}$ caused a small degree of bleaching ( $<4 \%$ in $100 \mathrm{~s}$; Figure 8), independent of laser photobleach $(65 \%)$. Epifluorescent measurement caused similar bleaching in terminals (Figure 8C, open circles) and somas (Figure 8D, open squares) of control cells. After subtracting the bleaching caused by epifluorescent measurements, the rate of FRAP by the laser exhibited a time constant $(\tau)$ of $38.3 \mathrm{~s}$
(Figure 8C, filled black circles) Without correcting $\tau$ for bleaching by the measurement light, terminal fluorescence recovered with $\tau=38.8 \mathrm{~s}$ (Figure 8C, filled red circles). Recovery of terminal fluorescence is due to dye molecules diffusing to the terminal from other parts of the cell, including the soma. We therefore measured fluorescence changes in the somas of cells whose terminals were photobleached. Before correcting for bleaching by the epifluorescent measurement light, the fluorescence intensity declined after laser photobleach more rapidly in somas of cells whose terminals were photobleached (Figure 8D, filled red squares) than in somas of control cells whose terminals were not photobleached (Figure 8D, open black squares). After correcting for bleaching by epifluorescent measurement, the fluorescence signal in the soma declined exponentially with $\tau=43.1 \mathrm{~s}$, close to the rate of FRAP in the terminal (Figure 8E). The amount of fluorescence decline in the soma caused by laser photobleach was much smaller than the amount of fluorescence recovered in the terminal, as expected from the much larger volume of ER in the soma. These results suggest that dye can diffuse from soma to terminal, restoring fluorescence in the terminal and slightly diminishing fluorescence in the soma.

The rate of fluorescence recovery in the terminal was consistent with the expected rate of diffusion of ER-tracker dye through the ER. The diffusion coefficient of $\mathrm{IP}_{3} \mathrm{R}_{1}$ receptors on ER membranes is $0.3 \mu \mathrm{m}^{2} / \mathrm{s}$ (Fukatsu et al., 2004) and ether-a-go-go (EAG) $\mathrm{K}^{+}$channels on the plasma membrane exhibit diffusion coefficients of $0.1-0.3 \mu \mathrm{m}^{2} / \mathrm{s}$ (Gómez-Varela et al., 2010). Assuming $\chi^{2}=2 \mathrm{Dt}$ and a diffusion coefficient of $0.3 \mu \mathrm{m}^{2} / \mathrm{s}$ for ATP-sensitive $\mathrm{K}^{+}$channels in ER, then channels would move an average of $\sim 5 \mu \mathrm{m}$ in $38 \mathrm{~s}$, similar to the distance from soma to terminal. Thus, results of FRAP experiments indicate that the ER forms a continuous structure extending from the terminal to soma in rods.

To visualize $\mathrm{ER} \mathrm{Ca}^{2+}$ levels of $60-400 \mu \mathrm{M}$ (Michalak et al., 2002), we loaded rods with a low affinity $\mathrm{Ca}^{2+}$ dye, fluo-5N AM $\left(K_{\mathrm{d}}=90 \mu \mathrm{M}\right)$. We then obtained whole cell patch clamp recordings using a $\mathrm{Ca}^{2+}$ - and dye-free pipette solution to wash dye out of the cytoplasm (Solovyova and Verkhratsky, 2002). Many brightly fluorescent areas were visible within terminals by TIRFM (Figure 9A; $n=6$ rods), consistent with that the pres-

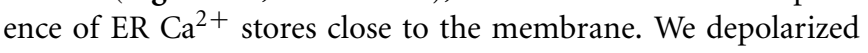
rods with 500-ms steps to test whether these bright areas represented functional intracellular $\mathrm{Ca}^{2+}$ stores mediating CICR. As illustrated in Figure 9, ER $\left[\mathrm{Ca}^{2+}\right]$ decreased in the terminal during the depolarizing step and recovered soon thereafter. This confirms that sustained depolarization releases $\mathrm{Ca}^{2+}$ from intracellular $\mathrm{Ca}^{2+}$ stores in rod terminals. Application of a 500ms depolarizing step caused only a very small decrease in soma ER $\left[\mathrm{Ca}^{2+}\right]$. Similar results were seen in four cells. The decrease in soma ER $\left[\mathrm{Ca}^{2+}\right]$ could be due to diffusion of $\mathrm{Ca}^{2+}$ through the ER from soma to terminal, although it might also be due to release of $\mathrm{Ca}^{2+}$ into the soma cytoplasm. Regardless, this result shows that release of $\mathrm{Ca}^{2+}$ from terminal ER did not significantly deplete $\mathrm{Ca}^{2+}$ from soma ER during a 500-ms step. Thus, soma $\mathrm{ER} \mathrm{Ca}^{2+}$ stores appear to have the capacity to sustain the transfer of $\mathrm{Ca}^{2+}$ from cell body to terminal during sustained depolarization. 

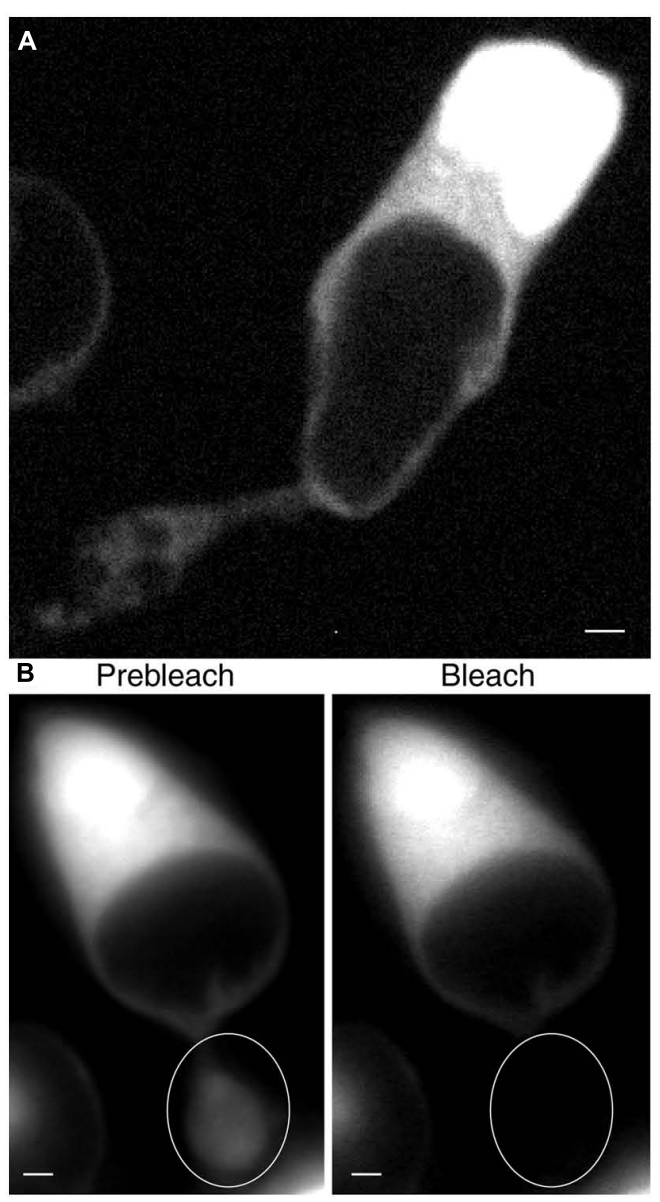

Bleach $+30 \mathrm{~s}$
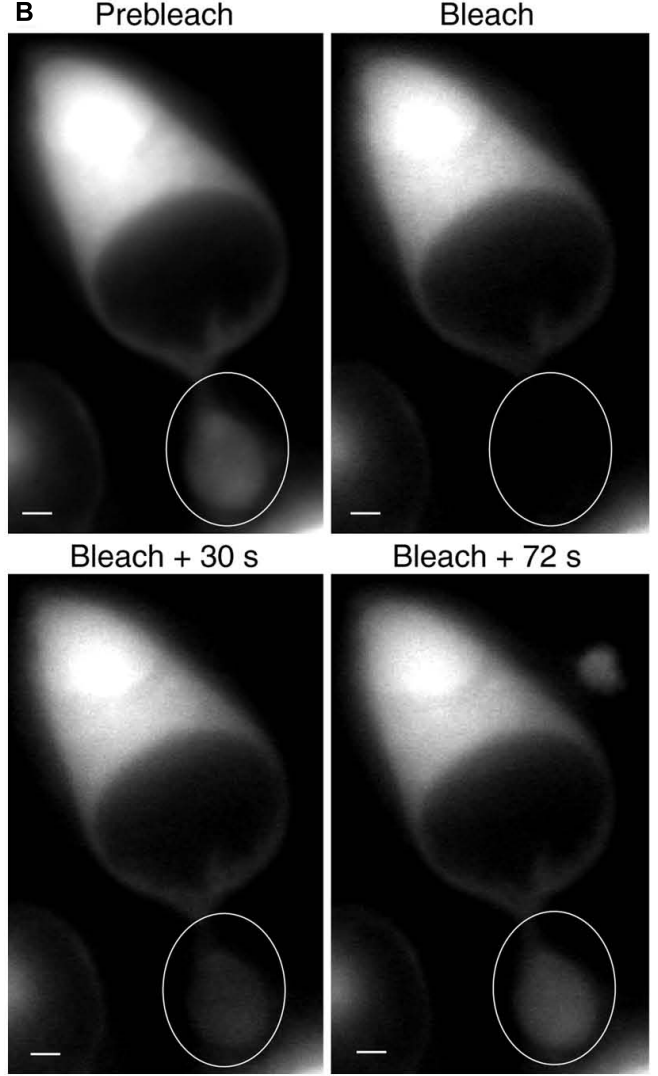

Bleach $+72 \mathrm{~s}$

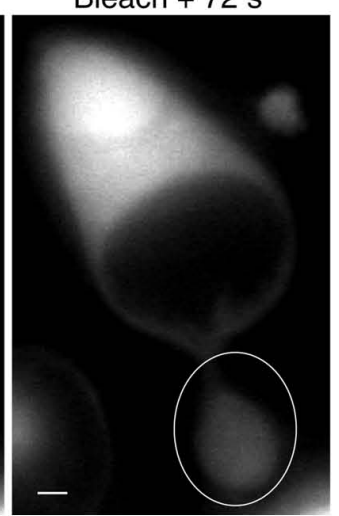

FIGURE 8 | Endoplasmic reticulum is continuous from soma to terminal. (A) A single confocal plane of an isolated rod labeled with ER-tracker green $(1 \mu \mathrm{M})$ and imaged with a spinning disk confocal microscope. Labeled intracellular structures are consistent with the presence of ER throughout the soma and terminal. (B) Series of images from an isolated rod loaded with ER-tracker green, showing fluorescence before and after laser photobleaching of the synaptic terminal (white circle). Scale bar: $2 \mu \mathrm{m}$. (C) The time course of fluorescence $\left(F / F_{0}\right)$ changes in terminals after photobleaching with 488-nm laser spot of $8 \mu \mathrm{m}$ in diameter (filled red circles). $F_{0}$ is the average fluorescence intensity in the terminal before bleaching. Fluorescence changes in control terminals that were not laser photobleached are also plotted ( $n=5$, open circles) to show bleaching caused by the epifluorescence illumination used to measure fluorescence recovery. The time course of fluorescence changes in terminals that were laser photobleached are also
C Terminal

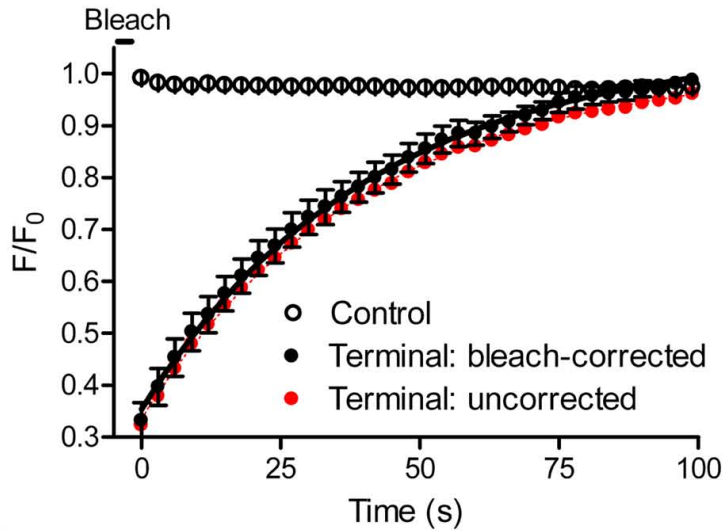

D Soma: uncorrected

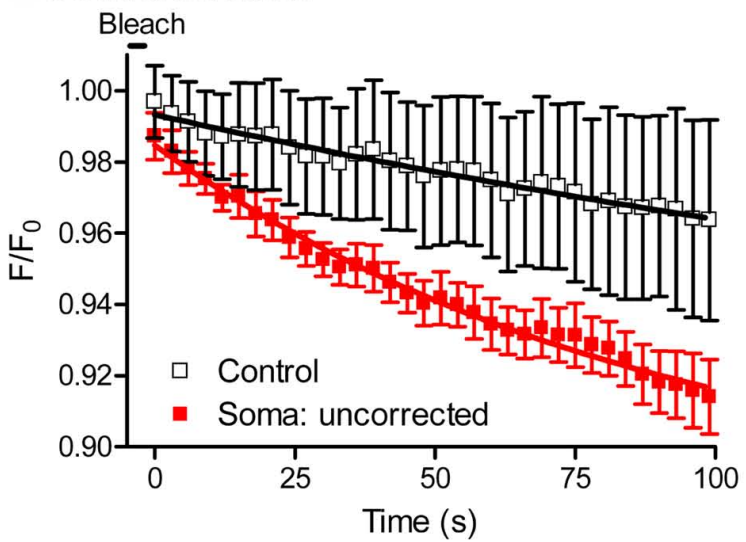

E Soma: bleach-corrected

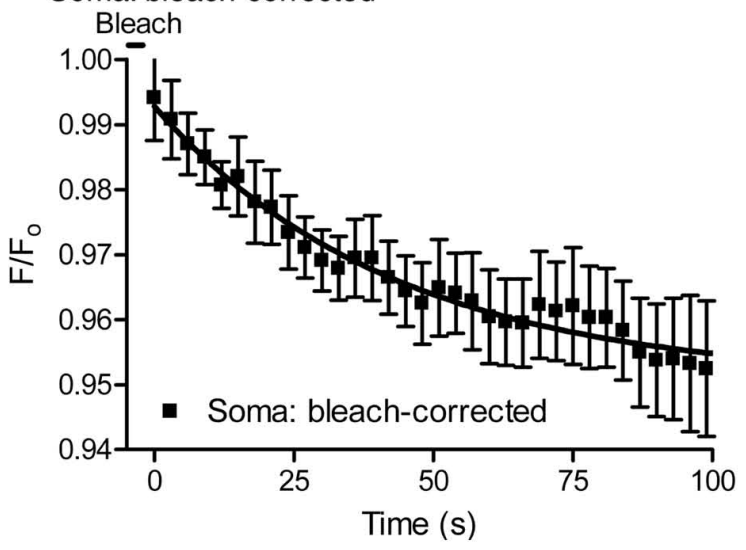

plotted after subtracting the bleaching caused by epifluorescent measurements (filled black circles). The solid black line shows an exponential fit to the fluorescence recovery in bleach-corrected terminals ( $\tau=38 \mathrm{~s}, n=6$ terminals). Photobleaching was triggered at time 0 and recovery was measured every $3 \mathrm{~s}$. (D) Time course of $F / F_{0}$ measured in the soma. Red squares show fluorescence changes in the somas of rods whose terminals were photobleached ( $\tau=90 \mathrm{~s}, n=6$ ). Black open squares show fluorescence changes in the somas of control rods whose terminals were not photobleached ( $\tau=278 \mathrm{~s}, n=6$ ). The small, slow fluorescence decline observed in somas of control rods whose terminals were not photobleached reflects the bleaching caused by epifluorescent measurements. (E) The rate of fluorescence decline in somas of rods with photobleached terminals after correcting for bleaching induced by epifluorescent measurements ( $t=43 \mathrm{~s}$; $n=6)$ 

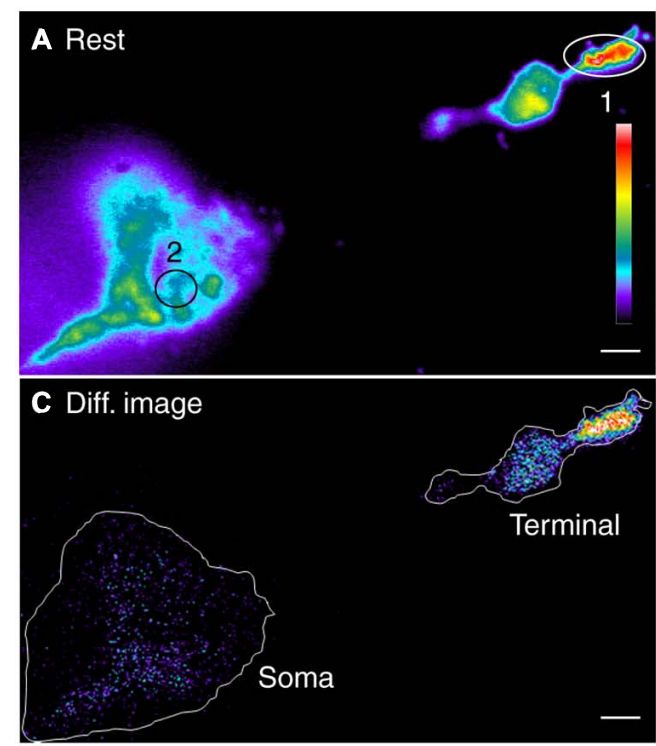

FIGURE 9 | Sustained depolarization depletes $\mathrm{Ca}^{2+}$ from intracellular stores in the terminal more than the soma. $(\mathbf{A}, \mathbf{B})$ The rod was loaded with a low affinity $\mathrm{Ca}^{2}+$ indicator, fluo-5N AM and then patched with a pipette containing $\mathrm{Ca}^{2+}$ - and dye-free solutions to wash dye out of the cytoplasm. Rods were depolarized for $500 \mathrm{~ms}$ from -70 to $-10 \mathrm{mV}$. Changes in ER $\left[\mathrm{Ca}^{2+}\right.$ ] were monitored using TIRFM at $22 \mathrm{~ms} /$ frame. (A) The resting pseudocolor image is the average of 20 frames before

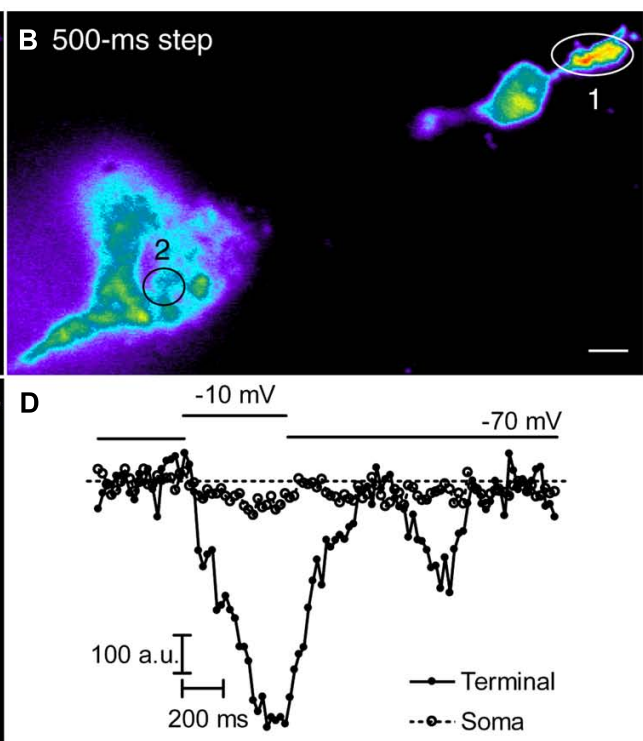

stimulation. (B) The depolarized pseudocolor image is the average of 15 frames during stimulation. (C) The difference pseudocolor image was obtained by subtracting the depolarized image from the resting image. In this difference image, hotter colors show larger declines in $E R\left[\mathrm{Ca}^{2+}\right]$. (D) The fluorescence intensities of fluo- $5 \mathrm{~N}$ in the terminal (region 1, filled circles) and soma (region 2, open circles) were plotted against time. Scale bar: $2 \mu \mathrm{m}$.

\section{DISCUSSION}

\section{CICR TRIGGERS RELEASE AT NON-RIBBON SITES}

Rather than simply facilitating release as found at a number of other synapses (Bouchard et al., 2003), we found that CICR directly triggers release at non-ribbon sites. The ability of CICR to trigger release directly is partly due to the ability of submicromolar $\left[\mathrm{Ca}^{2+}\right]$ to stimulate release from rods, much lower than the $\left[\mathrm{Ca}^{2+}\right]$ needed to stimulate release from other neurons (Rieke and Schwartz, 1996; Thoreson et al., 2004; Duncan et al., 2010). The principal ryanodine receptor subtype in rods is a variant of RyR2 (Shoshan-Barmatz et al., 2007). The probability of RyR2 opening can be regulated not only by local $\mathrm{Ca}^{2+}$ levels but also by phosphorylation, redox state, FK506-binding proteins, and other mechanisms (Zalk et al., 2007) suggesting that these factors may also be capable of regulating release.

Consistent with ultrastructural evidence of ER close to the plasma membrane in rod terminals (Mercurio and Holtzman, 1982; Babai etal., 2010b), activation of CICR stimulated submembrane $\mathrm{Ca}^{2+}$ increases throughout the terminal. Despite the fact that release-competent vesicles are concentrated near ribbons (Zenisek, 2008; Frank et al., 2010; Snellman et al., 2011), ryanodine triggered release almost exclusively at non-ribbon sites. The ineffectiveness of CICR in triggering release from ribbons may be due to a barrier that limits diffusion of $\mathrm{Ca}^{2+}$ or mobile $\mathrm{Ca}^{2+}$ buffers to and from ribbon release sites. Such a barrier was suggested by electrophysiological experiments with diffusible buffers (Bartoletti etal., 2011). Another possibility may be that the molecular mechanisms mediating exocytosis at non-ribbon sites differ from those mediating release at ribbon sites (e.g., by use of a different, higher affinity $\mathrm{Ca}^{2+}$ sensor).

Activation of CICR by repeated application of low concentrations of ryanodine triggered release at non-ribbon sites that varied in location from trial to trial. On the other hand, depolarization with $\mathrm{KCl}$ puffs, which stimulates release preferentially at ribbons (Chen et al., 2013), triggered release largely at fixed, reproducible locations. One possible interpretation of these data is that nonribbon release sites are not fixed, but mobile. Perhaps release at non-ribbon sites involves target-SNAREs (t-SNAREs) that wander freely about the rod terminal membrane after escaping endocytosis in perisynaptic regions (Wahl et al., 2013). However, non-ribbon release in bipolar cells occurs adjacent to relatively fixed postsynaptic densities (Midorikawa et al., 2007). Another possibility is that non-ribbon release in rods may also occur at fixed sites but with such low release probability that release rarely recurs at the same site in repeated trials.

\section{RELEASE AT PHOTORECEPTOR SYNAPSES}

Much of our current understanding of the mechanisms of release from photoreceptors is based on studies at cone synapses. In cones, the immediately releasable pool (IRP) of vesicles tethered at the base of the ribbon is replenished when they remain hyperpolarized in bright light. Subsequent membrane depolarization accompanying a decrement in light triggers the opening of L-type $\mathrm{Ca}^{2+}$ channels beneath the ribbon and stimulates the rapid release of vesicles (Bartoletti et al., 2010; Snellman et al., 2011). Release of a vesicle from the IRP in cones can be stimulated by the opening of $<3 \mathrm{Ca}^{2+}$ channels (Bartoletti et al., 2011). 
During maintained depolarization in darkness, the IRP is soon emptied (Jackman et al., 2009). After this pool has been emptied, the sustained release of vesicles by cones is no longer regulated by individual $\mathrm{Ca}^{2+}$ channel openings but is instead governed by the $\mathrm{Ca}^{2+}$-dependent delivery of release-competent vesicles to release sites at the base of the ribbon (Jackman et al., 2009; Babai et al., 2010a).

Li et al. (2010) showed that brief $1 \mathrm{~ms}$ test steps applied to ground squirrel rods can evoke fast EPSCs but did not report the effects of longer test steps. In amphibian retina, use of longer test steps evoke an initial burst of fast release followed by pronounced slow release (Cadetti et al., 2005; Rabl et al., 2005; Thoreson, 2007). Damaging rod ribbons by FALI diminished fast release measured both by paired recordings (Figure 1) and by capacitance techniques (Chen et al., 2013) indicating that the initial burst of release from rods involves the ribbon. Like cones, it is therefore also likely that some of the slow release from rods involves replenishment of ribbon-release sites. However, damaging rod ribbons did not significantly inhibit slow release suggesting that much of the slow release involves non-ribbon sites. Slow release is amplified by CICR in both amphibian and mammalian rods (Cadetti etal., 2006; Suryanarayanan and Slaughter, 2006; Babai et al., 2010b) and the present results showed that CICR promotes slow release by triggering vesicle fusion at non-ribbon sites. For example, when rods were stimulated with 500-ms depolarizing steps to activate $\mathrm{CICR}, \sim 50 \%$ of release events occurred $>1 \mu \mathrm{m}$ from the ribbon (Chen et al., 2013) and the present results showed that virtually all of the non-ribbon release events evoked by $500-\mathrm{ms}$ steps were triggered by CICR (Figure 5). The evidence for substantial non-ribbon release from rods in retinal slices obtained by FALI experiments suggests that non-ribbon release observed by TIRFM in isolated rods is not an artifact of cell isolation procedures.

Consistent with a significant role for non-ribbon release from rods, electron tomography studies revealed frequent exocytotic omega figures in non-ribbon regions of rod synapses (Zampighi et al., 2011). In addition, the absence of anchored ribbons in Bassoon mutant mice did not abolish visually guided behavior, visual cortical responses, or bipolar cell light responses assessed with the electroretinogram b-wave (Dick et al., 2003; Goetze et al., 2010). However, it is possible that the residual release in Bassoon mutants originates from a small number of intact ribbon synapses or release sites that contain the normal molecular machinery and would have been occupied by a ribbon (Dick et al., 2003). In support of a substantial role for CICR-triggered non-ribbon release, blocking CICR inhibited light responses of second-order neurons in amphibian retina by as much as 90\% (Cadetti et al., 2006; Suryanarayanan and Slaughter, 2006) and in mouse retina by $\sim 50 \%$ (Babai et al., 2010b).

The extent of non-ribbon release at other ribbon synapses is not clear. Release from $\mathrm{Ca}^{2+}$ stores has been implicated in driving sustained release from hair cells (Schnee et al., 2011). However, dissociating ribbons from the membrane by mutating the active zone protein bassoon decreased both fast and sustained release from hair cells (Khimich et al., 2005; Frank et al., 2010). Damaging ribbons by FALI reduced fast and sustained release equally in both cones and bipolar cells (Snellman et al., 2011), although TIRFM experiments also suggest a role for non-ribbon release in bipolar cells (Zenisek et al., 2004; Midorikawa et al., 2007; Zenisek, 2008).

\section{ER FACILITATES SUSTAINED RELEASE BY TRANSFERRING $\mathrm{Ca}^{2+}$ FROM SOMA TO TERMINAL}

The activation of CICR during sustained depolarization appears to provide supplemental $\mathrm{Ca}^{2+}$ that is essential for sustaining release from rods in darkness. This may be particularly important at rod synapses where the continued influx of $\mathrm{Ca}^{2+}$ during sustained depolarization can cause extracellular $\left[\mathrm{Ca}^{2+}\right]$ to decline significantly in the synaptic cleft (Rabl et al., 2003). This decline reduces the amplitude of $I_{\mathrm{Ca}}$ and thereby reduces sustained release.

Results from other polarized cells show that $\mathrm{Ca}^{2+}$ ions can "tunnel" through the ER from distant parts of the cell (Mogami et al., 1997; Park et al., 2000; Choi et al., 2006; Petersen and Verkhratsky, 2007). FRAP experiments with ER-tracker dye showed that the ER forms a continuous structure in rods, extending from terminal to soma. Along with ellipsoid mitochondria, ER in the cell body can store large amounts of $\mathrm{Ca}^{2+}$ (Michalak et al., 2002; Szikra and Krizaj, 2007). Consistent with this, 500-ms depolarizing steps depleted $\mathrm{Ca}^{2+}$ from terminal ER, but caused barely detectable reductions in soma ER. Furthermore, we found that CICR could be sustained in rod terminals by depolarizing stimuli lasting for $10 \mathrm{~s}$. Together, these results support the idea that $\mathrm{Ca}^{2+}$ may sustain CICR by tunneling through the ER from more distant reservoirs. As $\mathrm{Ca}^{2+}$ diffuses through the ER to the terminal to replenish ions depleted by CICR, $\mathrm{Ca}^{2+}$ can be restored to the ER in other parts of the cell by the actions of sarcoplasmic/ER Ca ${ }^{2+}$-ATPase type 2 (SERCA2) which pumps $\mathrm{Ca}^{2+}$ from the cytoplasm (Križaj, 2005). Store-operated $\mathrm{Ca}^{2+}$ entry also helps to regulate release from rods by elevating cytoplasmic $\mathrm{Ca}^{2+}$ and replenishing $\mathrm{ER} \mathrm{Ca}{ }^{2+}$ (Szikra et al., 2008; García-Sancho, 2014). Together, these non-conventional mechanisms appear to sustain CICR and may thereby sustain non-ribbon release in darkness.

\section{FUNCTIONAL IMPLICATIONS}

By triggering release at non-ribbon sites, CICR increases the total amount of slow release from rods thereby amplifying the rate of release in darkness. Elevated release in darkness enhances decrements in release that occur when rods hyperpolarize to light. Use of distant non-ribbon release sites may also have a secondary benefit of reducing synaptic noise by diffusional filtering of glutamate to post-synaptic glutamate receptors (DeVries et al., 2006). Together, these effects of CICR-mediated release at non-ribbon sites may improve the signal-to-noise ratio, enhancing contrast discrimination and the detection of small responses near visual threshold (Pahlberg and Sampath, 2011). Overall, the present results indicate that the triggering of release at non-ribbon sites by CICR is a major mechanism by which rods maintain the release of vesicles in darkness.

\section{ACKNOWLEDGMENTS}

This research was supported by the National Institutes of Health grants EY010542 (to Wallace B. Thoreson), EY010542S1 (to Wallace B. Thoreson), EY13870, EY14800 (to David Križaj), Research to Prevent Blindness (to Wallace B. Thoreson), and 
the UNMC graduate assistantship (to Minghui Chen). We thank Dr. David Zenisek for advice on TIRFM experiments and gift of Ribeye-binding peptides.

\section{REFERENCES}

Attwell, D., Wilson, M., and Wu, S. M. (1984). A quantitative analysis of interactions between photoreceptors in the salamander (Ambystoma) retina. J. Physiol. 352, 703-737.

Babai, N., Bartoletti, T. M., and Thoreson, W. B. (2010a). Calcium regulates vesicle replenishment at the cone ribbon synapse. J. Neurosci. 30, 15866-15877. doi: 10.1523/JNEUROSCI.2891-10.2010

Babai, N., Morgans, C. W., and Thoreson, W. B. (2010b). Calcium-induced calcium release contributes to synaptic release from mouse rod photoreceptors. Neuroscience 165, 1447-1456. doi: 10.1016/j.neuroscience.2009.11.032

Bardo, S., Robertson, B., and Stephens, G. J. (2002). Presynaptic internal $\mathrm{Ca}^{2+}$ stores contribute to inhibitory neurotransmitter release onto mouse cerebellar Purkinje cells. Br. J. Pharmacol. 137, 529-537. doi: 10.1038/sj.bjp.0704901

Bartoletti, T. M., Babai, N., and Thoreson, W. B. (2010). Vesicle pool size at the salamander cone ribbon synapse. J. Neurophysiol. 103, 419-423. doi: 10.1152/jn.00718.2009

Bartoletti, T. M., Jackman, S. L., Babai, N., Mercer, A. J., Kramer, R. H., and Thoreson, W. B. (2011). Release from the cone ribbon synapse under bright light conditions can be controlled by the opening of only a few $\mathrm{Ca}^{2+}$ channels. J. Neurophysiol. 106, 2922-2935. doi: 10.1152/jn.00634.2011

Benfenati, F., Valtorta, F., Bähler, M., and Greengard, P. (1989). Synapsin I, a neuronspecific phosphoprotein interacting with small synaptic vesicles and F-actin. Cell Biol. Int. Rep. 13, 1007-1021. doi: 10.1016/0309-1651(89)90016-7

Bouchard, R., Pattarini, R., and Geiger, J. D. (2003). Presence and functional significance of presynaptic ryanodine receptors. Prog. Neurobiol. 69, 391-418. doi: 10.1016/S0301-0082(03)00053-4

Cadetti, L., Bryson, E. J., Ciccone, C. A., Rabl, K., and Thoreson, W. B. (2006). Calcium-induced calcium release in rod photoreceptor terminals boosts synaptic transmission during maintained depolarization. Eur. J. Neurosci. 23, 2983-2990. doi: 10.1111/j.1460-9568.2006.04845.x

Cadetti, L., Tranchina, D., and Thoreson, W. B. (2005). A comparison of release kinetics and glutamate receptor properties in shaping rod-cone differences in EPSC kinetics in the salamander retina. J. Physiol. 569, 773-788. doi: 10.1113/jphysiol.2005.096545

Chen, M., Van Hook, M. J., Zenisek, D., and Thoreson, W. B. (2013). Properties of ribbon and non-ribbon release from rod photoreceptors revealed by visualizing individual synaptic vesicles. J. Neurosci. 33, 2071-2086. doi: 10.1523/JNEUROSCI.3426-12.2013

Choi, S. Y., Jackman, S., Thoreson, W. B., and Kramer, R. H. (2008). Light regulation of $\mathrm{Ca}^{2+}$ in the cone photoreceptor synaptic terminal. Vis. Neurosci. 25, 693-700. doi: 10.1017/S0952523808080814

Choi, Y. M., Kim, S. H., Chung, S., Uhm, D. Y., and Park, M. K. (2006). Regional interaction of endoplasmic reticulum $\mathrm{Ca}^{2+}$ signals between soma and dendrites through rapid luminal $\mathrm{Ca}^{2+}$ diffusion. J. Neurosci. 26, 12127-12136. doi: 10.1523/JNEUROSCI.3158-06.2006

DeVries, S. H., Li, W., and Saszik, S. (2006). Parallel processing in two transmitter microenvironments at the cone photoreceptor synapse. Neuron 50, 735-748. doi: 10.1016/j.neuron.2006.04.034

Dick, O., tom Dieck, S., Altrock, W. D., Ammermüller, J., Weiler, R., Garner, C. C., et al. (2003). The presynaptic active zone protein bassoon is essential for photoreceptor ribbon synapse formation in the retina. Neuron 37, 775-786. doi: 10.1016/S0896-6273(03)00086-2

Duncan, G., Rabl, K., Gemp, I., Heidelberger, R., and Thoreson, W. B. (2010). Quantitative analysis of synaptic release at the photoreceptor synapse. Biophys. J. 98, 2102-2110. doi: 10.1016/j.bpj.2010.02.003

Emptage, N. J., Reid, C. A., and Fine, A. (2001). Calcium stores in hippocampal synaptic boutons mediate short-term plasticity, store-operated $\mathrm{Ca}^{2+}$ entry, and spontaneous transmitter release. Neuron 29, 197-208. doi: 10.1016/S08966273(01)00190-8

Frank, T., Rutherford, M. A., Strenzke, N., Neef, A., Pangršič, T., Khimich, D., et al. (2010). Bassoon and the synaptic ribbon organize $\mathrm{Ca}^{2+}$ channels and vesicles to add release sites and promote refilling. Neuron 68, 724-738. doi: 10.1016/j.neuron.2010.10.027
Fukatsu, K., Bannai, H., Zhang, S., Nakamura, H., Inoue, T., and Mikoshiba, K. (2004). Lateral diffusion of inositol 1,4,5-trisphosphate receptor type 1 is regulated by actin filaments and $4.1 \mathrm{~N}$ in neuronal dendrites. J. Biol. Chem. 279, 48976-48982. doi: 10.1074/jbc.M408364200

Galante, M., and Marty, A. (2003). Presynaptic ryanodine-sensitive calcium stores contribute to evoke neurotransmitter release at the basket cell-Purkinje cell synapse. J. Neurosci. 23, 11229-11234.

García-Sancho, J. (2014). The coupling of plasma membrane calcium entry to calcium uptake by endoplasmic reticulum and mitochondria. J. Physiol. 592, 261-268. doi: 10.1113/jphysiol.2013.255661

Goetze, B., Schmidt, K. F., Lehmann, K., Altrock, W. D., Gundelfinger, E. D., and Löwel, S. (2010). Vision and visual cortical maps in mice with a photoreceptor synaptopathy: reduced but robust visual capabilities in the absence of synaptic ribbons. Neuroimage 49, 1622-1631. doi: 10.1016/j.neuroimage.2009.10.019

Gómez-Varela, D., Kohl, T., Schmidt, M., Rubio, M. E., Kawabe, H., Nehring, R. B., et al. (2010). Characterization of Eagl channel lateral mobility in rat hippocampal cultures by single-particle-tracking with quantum dots. PLOS ONE 5:e8858. doi: 10.1371/journal.pone.0008858

Hambrock, A., Löffler-Walz, C., and Quast, U. (2002). Glibenclamide binding to sulphonylurea receptor subtypes: dependence on adenine nucleotides. $\mathrm{Br}$. J. Pharmacol. 136, 995-1004. doi: 10.1038/sj.bjp.0704801

Hoffman-Kim, D., Diefenbach, T. J., Eustace, B. K., and Jay, D. G. (2007). Chromophore-assisted laser inactivation. Methods Cell Biol. 82, 335-354. doi: 10.1016/S0091-679X(06)82011-X

Holt, M., Cooke, A., Neef, A., and Lagnado, L. (2004). High mobility of vesicles supports continuous exocytosis at a ribbon synapse. Curr. Biol. 14, 173-183. doi: 10.1016/j.cub.2003.12.053

Jackman, S. L., Choi, S. Y., Thoreson, W. B., Rabl, K., Bartoletti, T. M., and Kramer, R. H. (2009). Role of the synaptic ribbon in transmitting the cone light response. Nat. Neurosci. 12, 303-310. doi: 10.1038/nn.2267

Khimich, D., Nouvian, R., Pujol, R., Tom Dieck, S., Egner, A., Gundelfinger, E. D., et al. (2005). Hair cell synaptic ribbons are essential for synchronous auditory signalling. Nature 434, 889-894. doi: 10.1038/nature03418

Križaj, D. (2005). Serca isoform expression in the mammalian retina. Exp. Eye Res. 81, 690-699. doi: 10.1016/j.exer.2005.04.007

Križaj, D., Bao, J. X., Schmitz, Y., Witkovsky, P., and Copenhagen, D. R. (1999). Caffeine-sensitive calcium stores regulate synaptic transmission from retinal rod photoreceptors. J. Neurosci. 19, 7249-7261.

Križaj, D., Lai, F. A., and Copenhagen, D. R. (2003). Ryanodine stores and calcium regulation in the inner segments of salamander rods and cones. J. Physiol. 547, 761-774. doi: 10.1113/jphysiol.2002.035683

Li, W., Chen, S., and DeVries, S. H. (2010). A fast rod photoreceptor signaling pathway in the mammalian retina. Nat. Neurosci. 13, 414-416. doi: $10.1038 / \mathrm{nn} .2507$

Llano, I., González, J., Caputo, C., Lai, F. A., Blayney, L. M., Tan, Y. P., et al. (2000). Presynaptic calcium stores underlie large-amplitude miniature IPSCs and spontaneous calcium transients. Nat. Neurosci. 3, 1256-1265. doi: 10.1038/81781

Ludwig, M., Bull, P. M., Tobin, V. A., Sabatier, N., Landgraf, R., Dayanithi, G., et al. (2005). Regulation of activity-dependent dendritic vasopressin release from rat supraoptic neurones. J. Physiol. 564, 515-522. doi: 10.1113/jphysiol.2005. 083931

Ludwig, M., Sabatier, N., Bull, P. M., Landgraf, R., Dayanithi, G., and Leng, G. (2002). Intracellular calcium stores regulate activity-dependent neuropeptide release from dendrites. Nature 418, 85-89. doi: 10.1038/nature 00822

Mercer, A. J., and Thoreson, W. B. (2011). The dynamic architecture of photoreceptor ribbon synapses: cytoskeletal, extracellular matrix, and intramembrane proteins. Vis. Neurosci. 28, 453-471. doi: 10.1017/S09525238110 00356

Mercurio, A. M., and Holtzman, E. (1982). Smooth endoplasmic reticulum and other agranular reticulum in frog retinal photoreceptors. J. Neurocytol. 11, 263293. doi: 10.1007/BF01258247

Michalak, M., Robert Parker, J. M., and Opas, M. (2002). Ca ${ }^{2+}$ signaling and calcium binding chaperones of the endoplasmic reticulum. Cell Calcium 32, 269-278. doi: 10.1016/S0143416002001884

Midorikawa, M., Tsukamoto, Y., Berglund, K., Ishii, M., and Tachibana, M. (2007). Different roles of ribbon-associated and ribbon-free active zones in retinal bipolar cells. Nat. Neurosci. 10, 1268-1276. doi: 10.1038/nn1963 
Mogami, H., Nakano, K., Tepikin, A. V., and Petersen, O. H. (1997). $\mathrm{Ca}^{2+}$ flow via tunnels in polarized cells: recharging of apical $\mathrm{Ca}^{2+}$ stores by focal $\mathrm{Ca}^{2+}$ entry through basal membrane patch. Cell 88, 49-55. doi: 10.1016/S00928674(00)81857-7

Nachman-Clewner, M., St Jules, R., and Townes-Anderson, E. (1999). Ltype calcium channels in the photoreceptor ribbon synapse: localization and role in plasticity. J. Comp. Neurol. 415, 1-16. doi: 10.1002/(SICI)10969861(19991206)415:1<1::AID-CNE1>3.0.CO;2-G

Nouvian, R., Neef, J., Bulankina, A. V., Reisinger, E., Pangršič, T., Frank, T., et al. (2011). Exocytosis at the hair cell ribbon synapse apparently operates without neuronal SNARE proteins. Nat. Neurosci. 14, 411-413. doi: 10.1038/nn. 2774

Pahlberg, J., and Sampath, A. P. (2011). Visual threshold is set by linear and nonlinear mechanisms in the retina that mitigate noise: how neural circuits in the retina improve the signal-to-noise ratio of the single-photon response. Bioessays 33 , 438-447. doi: 10.1002/bies.201100014

Park, M. K., Petersen, O. H., and Tepikin, A. V. (2000). The endoplasmic reticulum as one continuous $\mathrm{Ca}^{2+}$ pool: visualization of rapid $\mathrm{Ca}^{2+}$ movements and equilibration. EMBO J. 19, 5729-5739. doi: 10.1093/emboj/19. 21.5729

Petersen, O. H., and Verkhratsky, A. (2007). Endoplasmic reticulum calcium tunnels integrate signalling in polarised cells. Cell Calcium 42, 373-378. doi: 10.1016/j.ceca.2007.05.012

Rabl, K., Bryson, E. J., and Thoreson, W. B. (2003). Activation of glutamate transporters in rods inhibits presynaptic calcium currents. Vis. Neurosci. 20, 557-566. doi: $10.1017 /$ S0952523803205095

Rabl, K., Cadetti, L., and Thoreson, W. B. (2005). Kinetics of exocytosis is faster in cones than in rods. J. Neurosci. 25, 4633-4640. doi: 10.1523/JNEUROSCI.429804.2005

Ramakrishnan, N. A., Drescher, M. J., and Drescher, D. G. (2012). The SNARE complex in neuronal and sensory cells. Mol. Cell. Neurosci. 50, 58-69. doi: 10.1016/j.mcn.2012.03.009

Rea, R., Li, J., Dharia, A., Levitan, E. S., Sterling, P., and Kramer, R. H. (2004). Streamlined synaptic vesicle cycle in cone photoreceptor terminals. Neuron 41, 755-766. doi: 10.1016/S0896-6273(04)00088-1

Rieke, F., and Schwartz, E. A. (1996). Asynchronous transmitter release: control of exocytosis and endocytosis at the salamander rod synapse. J. Physiol. 493, $1-8$.

Schnapf, J. L., and Copenhagen, D. R. (1982). Differences in the kinetics of rod and cone synaptic transmission. Nature 296, 862-864. doi: 10.1038/296 $862 \mathrm{a} 0$

Schnee, M. E., Santos-Sacchi, J., Castellano-Muñoz, M., Kong, J. H., and Ricci, A. J. (2011). Calcium-dependent synaptic vesicle trafficking underlies indefatigable release at the hair cell afferent fiber synapse. Neuron 70, 326-338. doi: 10.1016/j.neuron.2011.01.031

Shakiryanova, D., Klose, M. K., Zhou, Y., Gu, T., Deitcher, D. L., Atwood, H. L., et al. (2007). Presynaptic ryanodine receptor-activated calmodulin kinase II increases vesicle mobility and potentiates neuropeptide release. J. Neurosci. 27, 7799-7806. doi: 10.1523/JNEUROSCI.1879-07.2007

Shakiryanova, D., Tully, A., Hewes, R. S., Deitcher, D. L., and Levitan, E. S. (2005). Activity-dependent liberation of synaptic neuropeptide vesicles. Nat. Neurosci. 8 , 173-178. doi: 10.1038/nn1377

Shoshan-Barmatz, V., Zakar, M., Shmuelivich, F., Nahon, E., and Vardi, N. (2007). Retina expresses a novel variant of the ryanodine receptor. Eur. J. Neurosci. 26, 3113-3125. doi: 10.1111/j.1460-9568.2007. 05931.x

Simkus, C. R., and Stricker, C. (2002). The contribution of intracellular calcium stores to mEPSCs recorded in layer II neurones of rat barrel cortex. J. Physiol. 545, 521-535. doi: 10.1113/jphysiol.2002. 022103

Snellman, J., Mehta, B., Babai, N., Bartoletti, T. M., Akmentin, W., Francis, A., etal. (2011). Acute destruction of the synaptic ribbon reveals a role for the ribbon in vesicle priming. Nat. Neurosci. 14, 1135-1141. doi: 10.1038/ $\mathrm{nn} .2870$

Solovyova, N., and Verkhratsky, A. (2002). Monitoring of free calcium in the neuronal endoplasmic reticulum: an overview of modern approaches. J. Neurosci. Methods 122, 1-12. doi: 10.1016/S0165-0270(02) 00300-X
Suryanarayanan, A., and Slaughter, M. M. (2006). Synaptic transmission mediated by internal calcium stores in rod photoreceptors. J. Neurosci. 26, 1759-1766. doi: 10.1523/JNEUROSCI.3895-05.2006

Szikra, T., Cusato, K., Thoreson, W. B., Barabas, P., Bartoletti, T. M., and Krizaj, D. (2008). Depletion of calcium stores regulates calcium influx and signal transmission in rod photoreceptors. J. Physiol. 586, 4859-4875. doi: 10.1113/jphysiol.2008.160051

Szikra, T., and Krizaj, D. (2007). Intracellular organelles and calcium homeostasis in rods and cones. Vis. Neurosci. 24, 733-743. doi: 10.1017/S09525238070 70587

Thoreson, W. B. (2007). Kinetics of synaptic transmission at ribbon synapses of rods and cones. Mol. Neurobiol. 36, 205-223. doi: 10.1007/s12035-0070019-9

Thoreson, W. B., Rabl, K., Townes-Anderson, E., and Heidelberger, R. (2004). A highly $\mathrm{Ca}^{2+}$-sensitive pool of vesicles contributes to linearity at the rod photoreceptor ribbon synapse. Neuron 42, 595-605. doi: 10.1016/S0896-6273(04) 00254-5

Tobin, V., Leng, G., and Ludwig, M. (2012). The involvement of actin, calcium channels and exocytosis proteins in somato-dendritic oxytocin and vasopressin release. Front. Physiol. 3:261. doi: 10.3389/fphys.2012. 00261

Tom Dieck, S., Altrock, W. D., Kessels, M. M., Qualmann, B., Regus, H., Brauner, D., et al. (2005). Molecular dissection of the photoreceptor ribbon synapse: physical interaction of Bassoon and RIBEYE is essential for the assembly of the ribbon complex. J. Cell Biol. 168, 825-836. doi: 10.1083/jcb.200 408157

Townes-Anderson, E., MacLeish, P. R., and Raviola, E. (1985). Rod cells dissociated from mature salamander retina: ultrastructure and uptake of horseradish peroxidase. J. Cell Biol. 100, 175-188. doi: 10.1083/jcb.100. 1.175

Trueta, C., Méndez, B., and De-Miguel, F. F. (2003). Somatic exocytosis of serotonin mediated by L-type calcium channels in cultured leech neurones. J. Physiol. 547, 405-416. doi: 10.1113/jphysiol.2002.030684

Van Hook, M. J., and Thoreson, W. B. (2013). Simultaneous whole-cell recordings from photoreceptors and second-order neurons in an amphibian retinal slice preparation. J. Vis. Exp. 76, e50007. doi: 10.3791/ 50007

Vessey, J. P., Lalonde, M. R., Mizan, H. A., Welch, N. C., Kelly, M. E., and Barnes, S. (2004). Carbenoxolone inhibition of voltage-gated Ca channels and synaptic transmission in the retina. J. Neurophysiol. 92, 1252-1256. doi: 10.1152/jn.00148.2004

Wahl, S., Katiyar, R., and Schmitz, F. (2013). A local, periactive zone endocytic machinery at photoreceptor synapses in close vicinity to synaptic ribbons. J. Neurosci. 33, 10278-10300. doi: 10.1523/JNEUROSCI.5048-12. 2013

Zalk, R., Lehnart, S. E., and Marks, A. R. (2007). Modulation of the ryanodine receptor and intracellular calcium. Annu. Rev. Biochem. 76, 367-385. doi: 10.1146/annurev.biochem.76.053105.094237

Zampighi, G. A., Schietroma, C., Zampighi, L. M., Woodruff, M., Wright, E. M., and Brecha, N. C. (2011). Conical tomography of a ribbon synapse: structural evidence for vesicle fusion. PLoS ONE 6:e16944. doi: 10.1371/journal.pone. 0016944

Zenisek, D. (2008). Vesicle association and exocytosis at ribbon and extraribbon sites in retinal bipolar cell presynaptic terminals. Proc. Natl. Acad. Sci. U.S.A. 105, 4922-4927. doi: 10.1073/pnas.0709067105

Zenisek, D., Horst, N. K., Merrifield, C., Sterling, P., and Matthews, G. (2004). Visualizing synaptic ribbons in the living cell. J. Neurosci. 24, 9752-9759. doi: 10.1523/JNEUROSCI.2886-04.2004

Zhang, J., and Wu, S. M. (2004). Connexin35/36 gap junction proteins are expressed in photoreceptors of the tiger salamander retina. J. Comp. Neurol. 470, 1-12. doi: 10.1002/cne.10967

Zhang, J., and Wu, S. M. (2005). Physiological properties of rod photoreceptor electrical coupling in the tiger salamander retina. J. Physiol. 564, 849-862. doi: 10.1113/jphysiol.2005.082859

Conflict of Interest Statement: The authors declare that the research was conducted in the absence of any commercial or financial relationships that could be construed as a potential conflict of interest. 
Received: 26 November 2013; accepted: 13 January 2014; published online: 03 February 2014

Citation: Chen M, Križaj D and Thoreson WB (2014) Intracellular calcium stores drive slow non-ribbon vesicle release from rod photoreceptors. Front. Cell. Neurosci. 8:20. doi: $10.3389 /$ fncel.2014.00020

This article was submitted to the journal Frontiers in Cellular Neuroscience.
Copyright (c) 2014 Chen, Križaj and Thoreson. This is an open-access article distributed under the terms of the Creative Commons Attribution License (CC BY). The use, distribution or reproduction in other forums is permitted, provided the original author(s) or licensor are credited and that the original publication in this journal is cited, in accordance with accepted academic practice. No use, distribution or reproduction is permitted which does not comply with these terms. 